Engineer Research and

Development Center

Army Environmental Quality Technology

\title{
Quantifying Impacts of Urban Growth Potential on Army Training Capabilities
}

Juliana McMillan-Wilhoit, Scott A. Tweddale,

September 2017

Michelle E. Swearingen, and James D. Westervelt 
The U.S. Army Engineer Research and Development Center (ERDC) solves the nation's toughest engineering and environmental challenges. ERDC develops innovative solutions in civil and military engineering, geospatial sciences, water resources, and environmental sciences for the Army, the Department of Defense, civilian agencies, and our nation's public good. Find out more at www.erdc.usace.army.mil.

To search for other technical reports published by ERDC, visit the ERDC online library at http:// acwc.sdp.sirsi.net/ client/ default. 


\section{Quantifying Impacts of Urban Growth Potential on Army Training Capabilities}

Juliana McMillan-Wilhoit, Scott A. Tweddale, Michelle E. Swearingen, and James D. Westervelt

Construction Engineering Research Laboratory

U.S. Army Engineer Research and Development Center 2902 Newmark Drive

Champaign, IL 61822

Final report

Approved for public release; distribution is unlimited.

Prepared for Office of the Assistant Secretary of the Army for Acquisition, Logistics, and Technology, ASA(ALT)

Washington, DC 20314-1000

Under Project P2 402188, “Integrated Climate Assessment for Army Enterprise Planning-Firing Range Capacity" 


\section{Abstract}

Building on previous studies of urban growth and population effects on U.S. military installations and training activities (e.g., Wilhoit et al. 2016), this report describes methodology and applies a methodology for quantifying urban development and encroachment impacts. The authors propose a distance-weighted assessment of population growth around the training areas to include both current population and projected urban growth. The results of this study demonstrate improvement over the previous methodology.

DISCLAIMER: The contents of this report are not to be used for advertising, publication, or promotional purposes. Citation of trade names does not constitute an official endorsement or approval of the use of such commercial products. All product names and trademarks cited are the property of their respective owners. The findings of this report are not to be construed as an official Department of the Army position unless so designated by other authorized documents. 


\section{Contents}

Abstract.............................................................................................................. ii

Figures and Tables..............................................................................................................v

Preface .........................................................................................................................vii

Unit Conversion Factors.......................................................................................viii

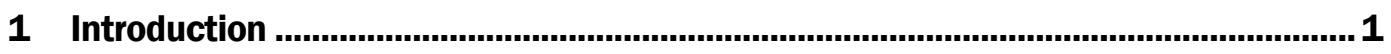

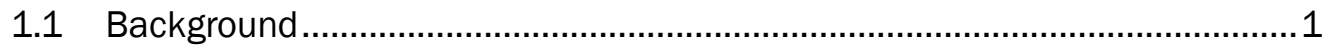

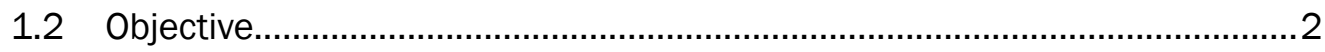

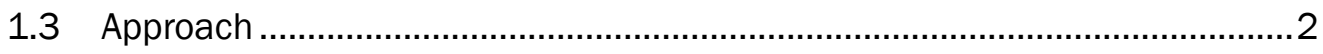

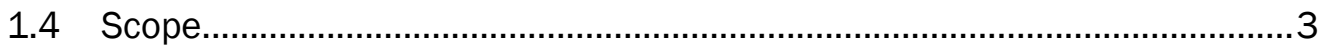

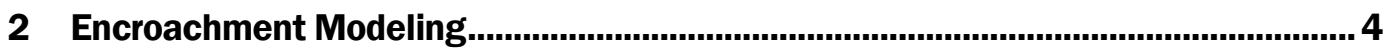

2.1 The Population Impact MVA attribute ...................................................... 4

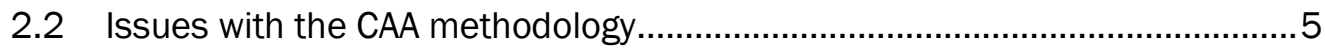

2.3 Considerations for revising current MVA method .......................................... 5

2.4 Additional proposed revisions ................................................................ 7

3 Analyzing Encroachment Through Urban Growth Modeling ................................ 9

3.1 Regional Urban Growth (RUG) model ...................................................... 9

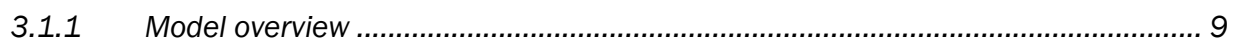

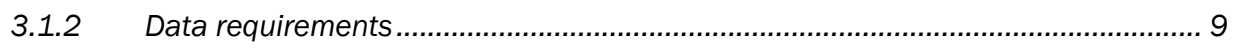

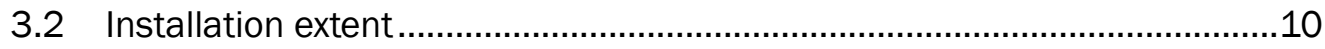

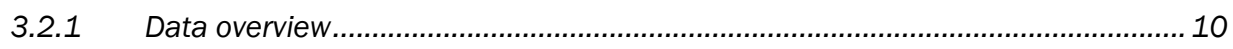

3.2.2 Data source for Army installation boundaries.................................................. 11

3.3 Training area boundaries and buffers ..............................................11

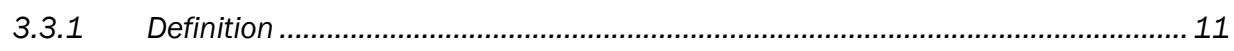

3.3.2 Data source for training areas ........................................................................ 12

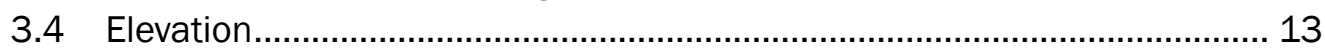

3.4.1 Data requirements and preparation ................................................................. 13

3.4.2 Process for obtaining DEM .......................................................................... 13

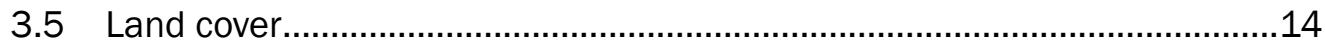

3.5.1 Data overview and preparation ................................................................. 14

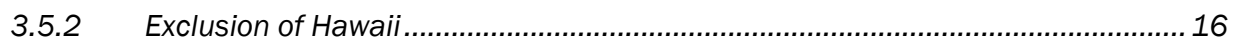

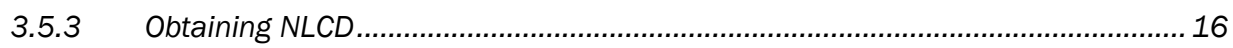

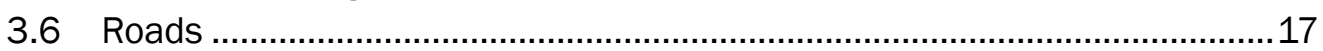

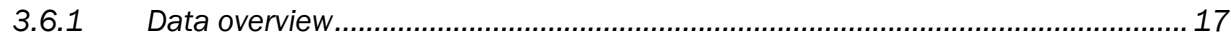

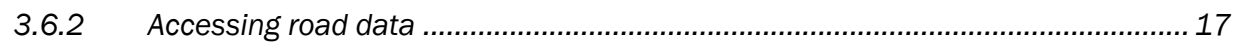

3.7 Flood hazard layer ..................................................................... 18

3.7.1 Data overview and preparation ........................................................................ 18

3.7.2 Accessing the national flood hazard layer.......................................................... 19

3.8 Protected areas............................................................................................ 


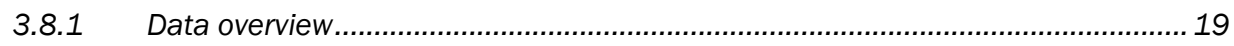

3.8.2 Obtaining protected areas data set ....................................................................... 20

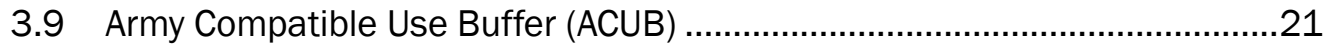

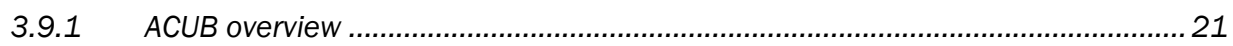

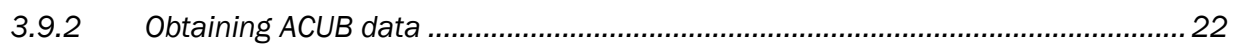

P.10 Population estimates from LandScan................................................ 22

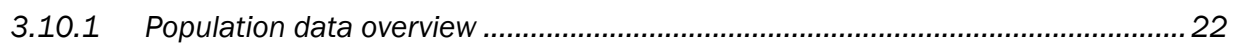

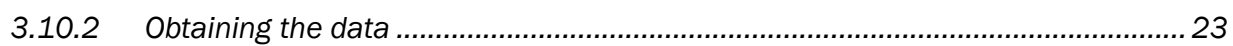

P.11 Preparing the data in ArcMap........................................................ 23

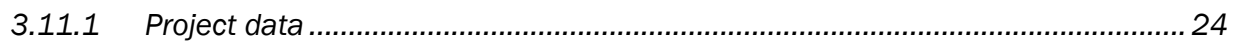

3.11.2 Run the data-preparation model................................................................... 25

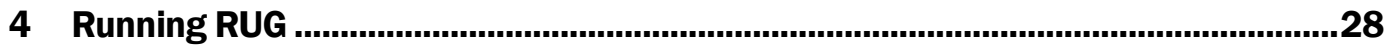

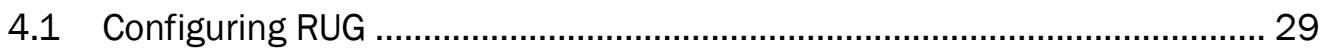

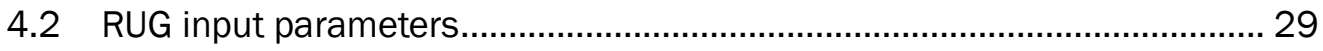

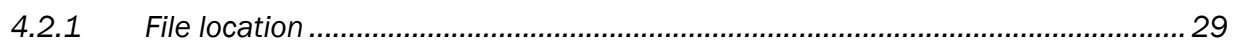

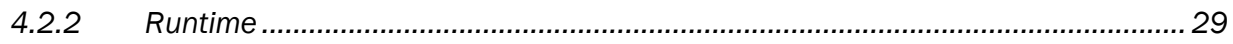

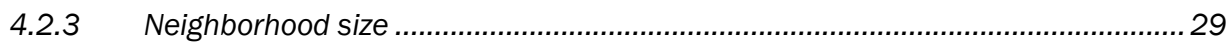

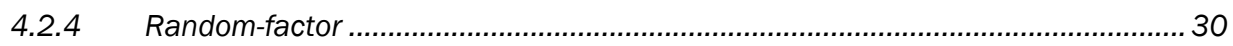

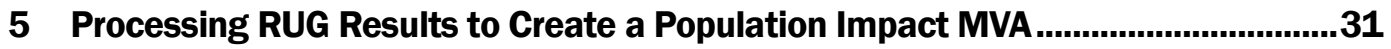

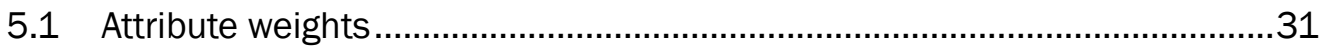

5.2 RUG Results folder ........................................................................ 32

5.3 Create Workspace folder ............................................................. 33

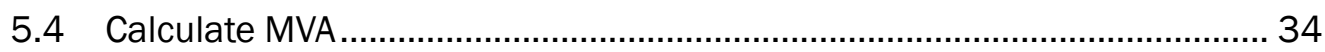

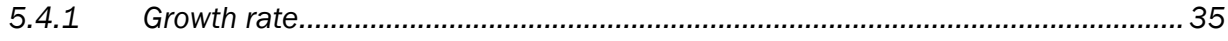

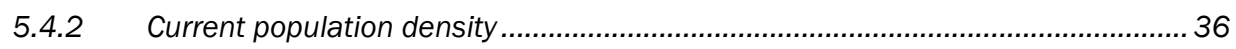

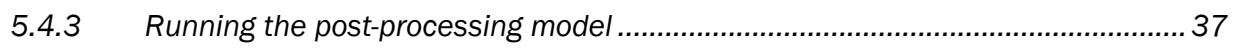

5.5 Results for sample installations .................................................... 39

6 Conclusions and Recommendations..................................................................42

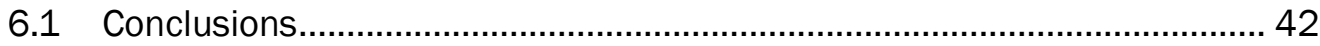

6.2 Recommendation ............................................................................... 43

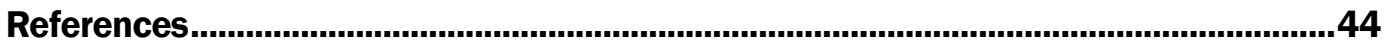

Appendix A: Current Population Impact MVA Definition (CAA 2015) ............................47

Appendix B: Proposed Population Impact MVA Definition ..............................................52

Appendix C: Errors Identified in Application..............................................................54

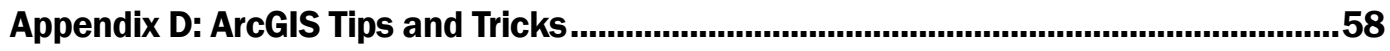

Appendix E: Data Dictionary for Headings in RUG Output..........................................60

Report Documentation Page 


\section{Figures and Tables}

\section{Figures}

Figure 1. Conceptual diagram outlining the necessary data sets and their

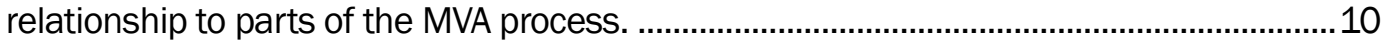

Figure 2. Map of the Army installations input data set.......................................................11

Figure 3. Map of the Army installations training areas data set. ........................................12

Figure 4. Map of the CONUS National Land Cover Database layer. ...................................15

Figure 5. Screen shot of the NLDC web-user interface .................................................... 17

Figure 6. Screenshot showing how to access the National Roads from the National Map Viewer. .................................................................................................

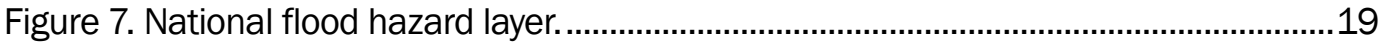

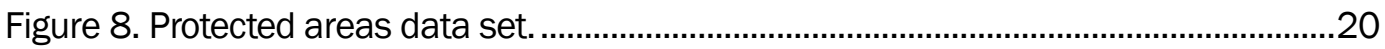

Figure 9. PAD-US download page showing correct selections..............................................21

Figure 10. CONUS population estimates from derived from LandScan..............................22

Figure 11. Screen shot of the Population Impact Data Processing Model developed for ArcMap which prepares data sets for use in RUG........................................25

Figure 12. Results produced by RUG shown in ArcCatalog window prior to MVA

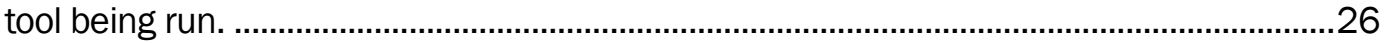

Figure 13. Graphical user interface for RUG................................................................28

Figure 14. Graphic representation of MVA calculation.......................................................31

Figure 15. Demonstration of the results folder and its contents after running

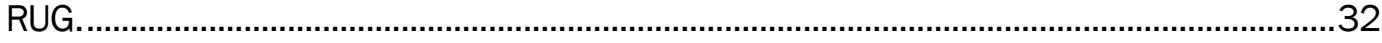

Figure 16. Screen shot of the Create Workspace tool......................................................33

Figure 17. Common error message received when workspace folder is not created before running the MVA calculation tool. ...........................................................34

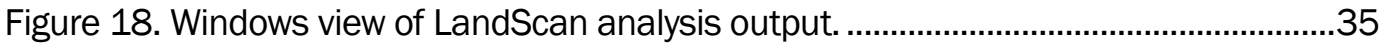

Figure 19. ArcCatalog view of LandScan analysis output...............................................35

Figure 20. Screen shot of the MVA calculation tool showing fields for selecting

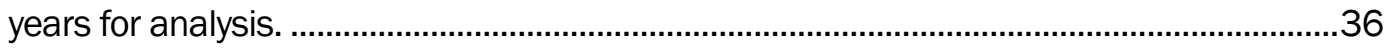

Figure 21. Screen shot of the model dialog to produce an MVA.........................................38

Figure 22. Results from this methodology plotted to demonstrate the linear path. ..........40

Figure 23. Comparison of result curve for each of the population impact methodologies.

\section{Tables}

Table 1. Summary of the inputs required for the preprocessing model. .............................26

Table 2. Proposed Population Impact MVA weights...........................................................32

Table 3. Summary of the parameters for the model to compute an MVA. ..........................38

Table 4. Summary of MVA results. ..................................................................................39 
Table 5 Comparison of the three iterations of MVA score calculation per

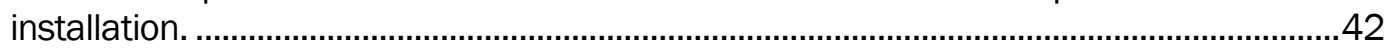




\section{Preface}

This study was conducted for the Office of the Assistant Secretary of the Army for Acquisition, Logistics, and Technology, ASA(ALT) under Program Element 622720A896, "Army Environmental Quality Technology"; Project P2 402188, "Integrated Climate Assessment for Army Enterprise Planning- Firing Range Capacity." The project technical monitor was Alan B. Anderson, CEERD-CZT, Technical Director for Military Lands.

The work was performed by the Ecological Processes Branch (CNN) of the Installations Division (CN), U.S. Army Engineer Research and Development Center, Construction Engineering Research Laboratory (ERDCCERL). At the time of publication, Dr. Chris C. Rewerts was Chief, CEERD-CNN; and Michelle J. Hanson was Chief, CEERD-CN. The Deputy Director of ERDC-CERL was Dr. Kirankumar Topudurti and the Director was Dr. Ilker Adiguzel.

The Commander of ERDC was COL Bryan S. Green and the Director was Dr. David W. Pittman. 


\section{Unit Conversion Factors}

\begin{tabular}{|c|c|c|}
\hline Multiply & By & To Obtain \\
\hline acres & $4,046.873$ & square meters \\
\hline acre-feet & $1,233.5$ & cubic meters \\
\hline feet & 0.3048 & meters \\
\hline square feet & 0.09290304 & square meters \\
\hline square inches & 6.4516 E-04 & square meters \\
\hline square miles & $2.589998 E+06$ & square meters \\
\hline yards & 0.9144 & meters \\
\hline
\end{tabular}




\section{Introduction}

\subsection{Background}

U.S. Army stationing is a continuous, multiscale process. Army personnel and assigned duty stations are in a constant state of flux. Army Regulation AR 10-5, Organization and Functions (HQDA 1992), guides most stationing processes. Due to its complexity, large-scale stationing - which is identified with strategic realignments-requires mathematical modeling to help determine whether the movement of tactical equipment and large numbers of personnel continues to meet future long-term strategic requirements written in the Army Campaign Plan while decreasing infrastructure budget requirements. The Center for Army Analysis (CAA), the Army's center of expertise on large-scale modeling and analysis, is often tasked to lead the analysis in large-scale personnel realignments as part of the AR 10-5 process. The largest stationing efforts the CAA supports for the Department of Defense (DoD) is the congressionally mandated Base Realignment and Closure (BRAC) process. The CAA also performs smaller stationing exercises such as the European Stationing and brigade combat team studies.

CAA has developed an iterative process that builds on Military Value Analysis (MVA) models that include a set of attributes that define the military value of installations. MVA analysis provides installation rankings and scores that form the basis for all analyses and recommendations, including input to the Optimal Stationing of Armed Forces (OSAF) model. OSAF and MVA outputs, as well as subject-matter expert (SME) insights, are combined to produce potential scenarios that are then placed into the Cost of Base Realignment Actions (COBRA) model to determine a scenario's cost. This iterative analysis prioritizes the potential scenarios to yield final Courses of Action (COAs) and recommendations. Although the stationing decision analysis process has worked well in the past, the CAA seeks to improve the methods for use in future stationing analyses.

Encroachment of urban development upon military installations can be expected to have an impact on the Army's costs and ability to fulfill its missions due to issues "related to noise complaints, reduction of natural buffer land surrounding installation boundaries, light-pollution effects on nighttime training operations, and other potential impacts to operations 
on installations" (CAA 2015). Therefore, urban encroachment is used by CAA in stationing analysis as the Population Impact attribute in the MVA. The Population Impact attribute attempts to "address potentially negative impacts on an installation and the nearby communities created by changes in population of the surrounding area over time."

The Army needs an accurate understanding of how major military realignments may further exacerbate, or may be affected by, existing and potential future urban encroachment on installations. Stationing analysis done with urban encroachment in mind recognizes an unpredictable future while striving to best prepare for the potential consequences if encroachment begins or increases. The inclusion of these factors provides a stationing analysis process that allows for a better-informed MVA modeling and cost analysis. The focus of this research was to make improvements to the Population Impact attribute and to automate methods for calculating it.

\subsection{Objective}

The overall objective of this work was to develop and document a proposed metric for the analysis of urban encroachment using modeling technology to project the future land-development footprint adjacent to any Army installation of interest.

\subsection{Approach}

In previous work, a distance-weighted assessment of population growth around the training areas was proposed and implemented. A complete overview of this distance-weighted assessment of population growth and its implementation in conjunction with the RUG model to calculate a Population Impact MVA is provided in Wilhoit et al. 2016. (Some later refinements of that assessment process are outlined in Chapter 2.)

In this report, detailed instructions are provided on acquiring and preprocessing national-scale geospatial data for input to RUG. Also, detailed instructions are presented for executing RUG and the MVA model to calculate the final MVA attribute.

The objectives of the present work were met in two principal activities. 
First, in order to improve methods to estimate the impact of population growth in an installation's surrounding area, the following tasks were accomplished:

- Existing methods for evaluating these factors were examined.

- The methods were then modified and/ or updated to better capture the true impact. For the population-impact case, the initial method examined was the Military Value Attribute called Population Impact.

- Subject-matter experts (SMEs) were consulted to reveal previously overlooked factors of interest, such as Army Compatible Use Buffers (ACUB) and satellite training locations. These factors were included in the analysis of population impact.

- An updated methodology, including realistic urban growth projections and graded distance buffer zones, was developed. To facilitate comparison to the current methodology, the updated method is presented in the form of an MVA attribute.

Second, data specifications were developed for an application of the Regional Urban Growth modeling platform in order to automate calculation of the Population Impact attribute so that it can be rapidly projected for any set of military installations under consideration in a stationing analysis.

\subsection{Scope}

This work explored the ability of U.S. Army installations in the Continental United States (CONUS) and Alaska to support firing range and maneuver area training with population pressures in surrounding communities. Methods and tools were developed to support a nationwide analysis. This study focused on installations operating training areas that were highlighted as key areas by the CAA. An MVA attribute was then calculated for a larger set of installations using the new method. 


\section{Encroachment Modeling}

\subsection{The Population Impact MVA attribute}

Encroachment is an important consideration in stationing decisions. Currently, encroachment is used by CAA in stationing analysis as the Population Impact attribute in the military value assessment (MVA). This definition is included in Appendix A for reference. The Population Impact MVA attempts to "address potentially negative impacts on an installation and the nearby communities created by changes in population of the surrounding area over time" (CAA 2015). This is measured through two factors: (1) the population density within a 10 mile buffer zone around the installation and (2) a growth factor based on the change in population between the last two censuses. The attribute is an indicator of encroachment issues that is used to assess the impact of population and population growth on the installation and that serves as "an indicator of potential encroachment issues relating to noise complaints, reduction of natural buffer land surrounding installation boundaries, light-pollution effects on nighttime training operations, and other potential impacts to operations on installations" (CAA 2015).

According to the methods currently used by CAA, new encroachment hazards are defined by using the 10 year growth rate and are calculated within a 10 mile buffer of an installations fence-line (CAA 2015). This calculation assumes that the growth rate for the 10 mile buffer is equal across the area since it is the average of the growth rates of each census block within the buffer. This assumption, however, could lead to erroneous predictions because growth may vary widely in the study area. For example, the area just outside of the main gate of an installation could be growing rapidly while areas closer to the training ranges may not be growing at such a high rate. An assessment that averages the growth rates over the entire buffer area and assumes that growth is occurring at that rate through the entire region may erroneously identify a potential problem area. Conversely, if the areas near the training ranges grow rapidly, but growth in the more densely populated areas has slowed significantly, a potential problem area might be overlooked. Identifying the growth rate at distances under 10 miles will greatly improve the assessment of the impact of population growth on the installation. 


\subsection{Opportunities to improve CAA methodology}

A method for calculating the Population Impact MVA developed by Wilhoit et al. (2016) outlines specific challenges with the methodology used by CAA. The MVA attribute definition provides a generalized indicator of the potential for future encroachment issues. While it is useful to have information regarding population densities around military installations as an encroachment indicator, the methods used do not adequately relate significance to the locations and projected growth rates of the population centers. Encroachment (noise, dust, radio frequency availability, and light pollution) are dependent on the locations of the residential centers. Synchronizing the encroachment factors and projected urban growth would result in a more meaningful assessment of the impact of urban sprawt.

Using a linear growth model, based on the previous 10 years of growth, does not adequately portray the potential urban growth in an area. Multiple factors, such as availability of space for housing, economic resiliency, and desirability of a location, all influence the actual growth in an area. Additionally, long-term growth tends to level off when an area reaches a saturation point, an effect not captured in a linear growth model. A linear model also fails to capture the effects of a significant influx or outflow of population due to external drivers, such as a major stationing decision. Finally, if a significant population event occurred within or just after the timeframe, the growth rate could be skewed.

\subsection{Considerations for revising current MVA method}

This report, as well as the preceding report by Wilhoit et al. (2016), provide clear recommendations for improvements to the population impact assessment. To address the challenges of using aggregated linear growth, seven prospective changes were investigated:

\section{Use of urban-growth modeling rather than linear-population} change: An urban growth model is a spatial model that predicts which land will develop in the future. As an alternative the use of the RUG model to simulate future encroachment risks and their proximity to an installation was investigated.

2. Use of a modified growth rate rather than a standard growth rate: Because population impact is a sum of normalized scores, results can be heavily skewed if the data are not normally distributed. It was found that some installations with small surrounding population (e.g., 
Fort Irwin) had estimated growth rates of over 300\%. This type of result not only skewed the normalization, but also did not adequately represent the encroachment risk at the installation since very little land was developed. The proposed alternative is to use change in the percentage of land developed within a buffer.

3. Use of LandScan Population Data: The proposed alternative to using U.S. Census block data is LandScan population estimates from Oak Ridge National Laboratory. This data set, ${ }^{*}$ provided free of charge to the federal government, reduces processing time and, because it provides population estimates at 30 meter resolution, allows users to develop population estimations at scales below 10 miles.

4. Use of areas less than 10 miles: By changing data sources to LandScan for population density and an urban growth model for growth rate, population estimates are provided at a resolution finer than 10 miles used in the current method.

5. Measurement from ranges: The current population impact attribute uses a 10 mile buffer from the installation's fenceline to calculate population. A 10 mile area was selected by subject matter experts, based on factors such as noise, road infrastructure, and a comparison of the population densities around the installations (CAA 2015). The greatest impact of urban growth surrounding an installation comes from growth near the training areas, not the cantonment area. Therefore, training-land proximity was incorporated as opposed to the entire fenceline as the buffering point.

6. Incorporate satellite training areas into analysis: The current population impact attribute only measures from the installation's main fenceline. The present analysis includes non-adjacent training areas that are associated with an installation. After conversations with Army Environmental Command personnel, we were not able to locate an official list pairing satellite training areas to installations. Therefore, in the event of a stationing event, the most effective approach would be to identify satellite training areas through a data call from installations.

7. Give weight to installations with ACUB land: The Army Compatible Use Buffer (ACUB) Program is a tool to protect an installations accessibility, availability, and capability for training, testing, and operations by sustaining natural habitats, open space, working lands,

\footnotetext{
* In this report the term "data set" is treated as two words except where external source material or computer code present it as the closed-up compound term "dataset."
} 
cultural resources, and communities. ACUB land shapefiles were provided by the ACUB team. These were made into "no-growth" areas in our urban growth model. Installations with ACUB programs therefore will not have development projections in these parcels. A weighting scheme for the final MVA score which provides a bonus point for installations with ACUB programs was also proposed.

\subsection{Additional proposed revisions}

Subsequent to the publication of Wilhoit et al. (2016), the authors made several changes and improvements in the methodology described in that report. A proposed new MVA attribute can be found in Appendix B. These changes were the results of additional testing and literature review, and it is believed they produce a product that provides better results. They are briefly described below:

1. Change in regional definition: There is no national data set that contains regional definitions. Consequently, it was necessary to develop our own way to define study regions. The present work utilized a 20 mile buffer around the installations, in contrast to Wilhoit et al. (2016) which defined the region by counties. This eliminated the problem of having very large counties in the surrounding areas of some installations, which resulted in very large study regions. The previous inclusion of such large regions also may have skewed the results, as some very large counties may have had large population growth which that a result of urban sprawl and development in an adjacent county.

2. NLCD change map rather than population change: The NLCD change map was used to determine the input growth rate to RUG instead of using population growth extracted from census data. This resulted in an annual, locally NLCD-calibrated estimate of percent growth. Since the NLCD change map was utilized to estimate growth rate, the estimate was derived from 2006- 2011 rather than the 19802012 time period used in Wilhoit et al. 2016.

3. Regionally specific neighborhood sizes: One of the parameters in RUG is the size of neighborhoods, or clumping of developments. Previously this was a variable, and was set to 0 in the work outlined in Wilhoit et al. 2016. In this research the neighborhood size input parameter to RUG was modified to reflect the "typical" neighborhood sizes found in the NLCD change map, thereby producing more realistic sizes of projected neighborhood growth which were based on local conditions. The previous methodology allowed projected growth to be allocated to 
isolated pixels rather than forcing new development to occur in clusters or neighborhoods of pixels. In this analysis, however, a list of all of the neighborhood sizes of "clumps" of pixels identified as changed in the NLCD change map was compiled. Using this list, a neighborhood size coefficient was randomly selected each time projected urban growth pixels were added to the map.

4. Development attractiveness: When using the NLCD change map to delineate where urban development has recently occurred, it was assumed that these developments reflect the land's current attractiveness for development. This map is used to calibrate the equations used to calculate the attractiveness of every grid cell across the study area. Previously, all urban categories in the NLCD change map were used to calibrate the RUG equations, whereas in this research, "21 - commercial" and " 24 - high intensity residential" land cover categories were eliminated, and only " 22 - lowintensity residential" and " 23 - medium intensity residential" land cover categories were used.

5. Inclusion of Flood Hazard: In the present analysis we additionally included the 100 year and 500 year flood zones available from FEMA. These data were included as a way to integrate a climate factor into the assessment. The flood hazard data was integrated as an attractor for development, and the logistic regression model determined if it was positively or negatively correlated with development. The authors' hypothesis was that the flood hazard areas would be detractors for development because of the cost of carrying insurance and the risk of flood damage. For this assessment of 22 installations, flood hazard areas had a negative or neutral relationship with development in nine of the installations. In the other twelve, the flood zones were positively correlated with growth. This result could indicate that the risk of a flood is outweighed by the perceived benefits of the location, such as being close to a body of water. 


\section{Analyzing Encroachment Through Urban Growth Modeling}

\subsection{Regional Urban Growth (RUG) model}

\subsubsection{Model overview}

Developing a solution toward estimating encroachment impacts from population relies on the RUG model. ${ }^{*}$ RUG produces a spatially explicit estimate of future urban growth based on data and user input to the model. The purpose of the RUG model is to generate residential attractiveness maps and growth projections that are based on nationally available data sets and require little human intervention to produce. RUG is a software tool intended to be rapidly implemented by a planner with reasonable GIS knowledge, or a GIS technician with little requisite simulation expertise. Because RUG is DoD owned and managed software, it has the greatest potential for reliable access and adaptability. RUG can be rapidly installed, parameterized, calibrated, and run on almost any multiple-county region within the United States (Westervelt, BenDor, and Sexton 2011).

\subsubsection{Data requirements}

The RUG model depends on ten ArcGIS ASCII grid data sets to run the model for input to the Population Impact MVA. This section outlines the custom ArcGIS data-preparation tool developed to preprocess nationalscale geospatial data in order to produce the required data for running in RUG. The custom AroGIS data-preparation tool also produces tabular output summarizing population sizes which is used in the post-processing model to calculate the Population Impact MVA attribute (see Figure 1).

Eleven GIS data sets (seven vector and four raster) are required as inputs to the data-preparation tool, which then produces the ten ASCII grid data sets that are required to conduct encroachment analysis using RUG.

\footnotetext{
* For a detailed analysis of why the RUG model was selected, please see Wilhoit et al. 2016.
} 
Figure 1. Conceptual diagram outlining the necessary data sets and their relationship to parts of the MVA process.

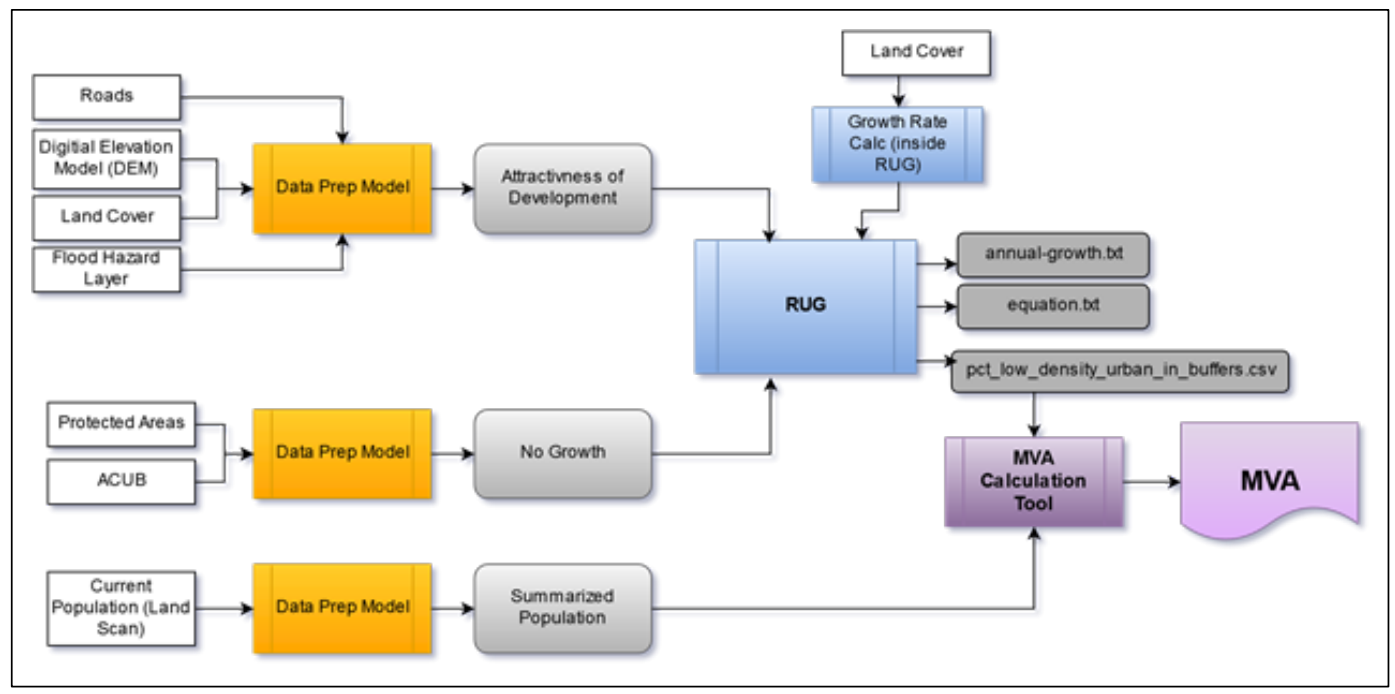

\subsection{Installation extent}

\subsubsection{Data overview}

Since this methodology is being developed to assess encroachment surrounding Army installations, the location of Army installations is an important starting point. The Army installation's location will then determine the region and the extent of the analysis which is to be conducted. All example results provided in the report utilized a distance of 20 miles from the installation boundary to define the extent of the analysis. This distance defines the extent of the analysis area and is different than the buffer distances described in section 3.3, where buffers of varying distances from the training areas on an installation are calculated to weight the impact of development on the installation based on its proximity to the base. For the data to be prepared correctly, the user must provide an ArcGIS vector shapefile containing the boundaries for installations to be analyzed where each record is a different installation. The user must also define the field which contains the installation's name in the tool.

The data processing model creates an ASCII raster grid of the region based on a distance of 20 miles from each of the installation boundaries of interest. Areas within the study areas are coded with a value of " 1 " and the remainder of the area with a value of no data. All other GIS data layers are clipped to this boundary of the study area. 


\subsubsection{Data source for Army installation boundaries}

This analysis relies upon the notional boundaries of Army installations rather than their legal boundaries as of spring 2016 (Figure 2). The official Army record of installation boundaries is with the Army Mapper Program (http:// mapper.army.mil/).

Figure 2. Map of the Army installations input data set.

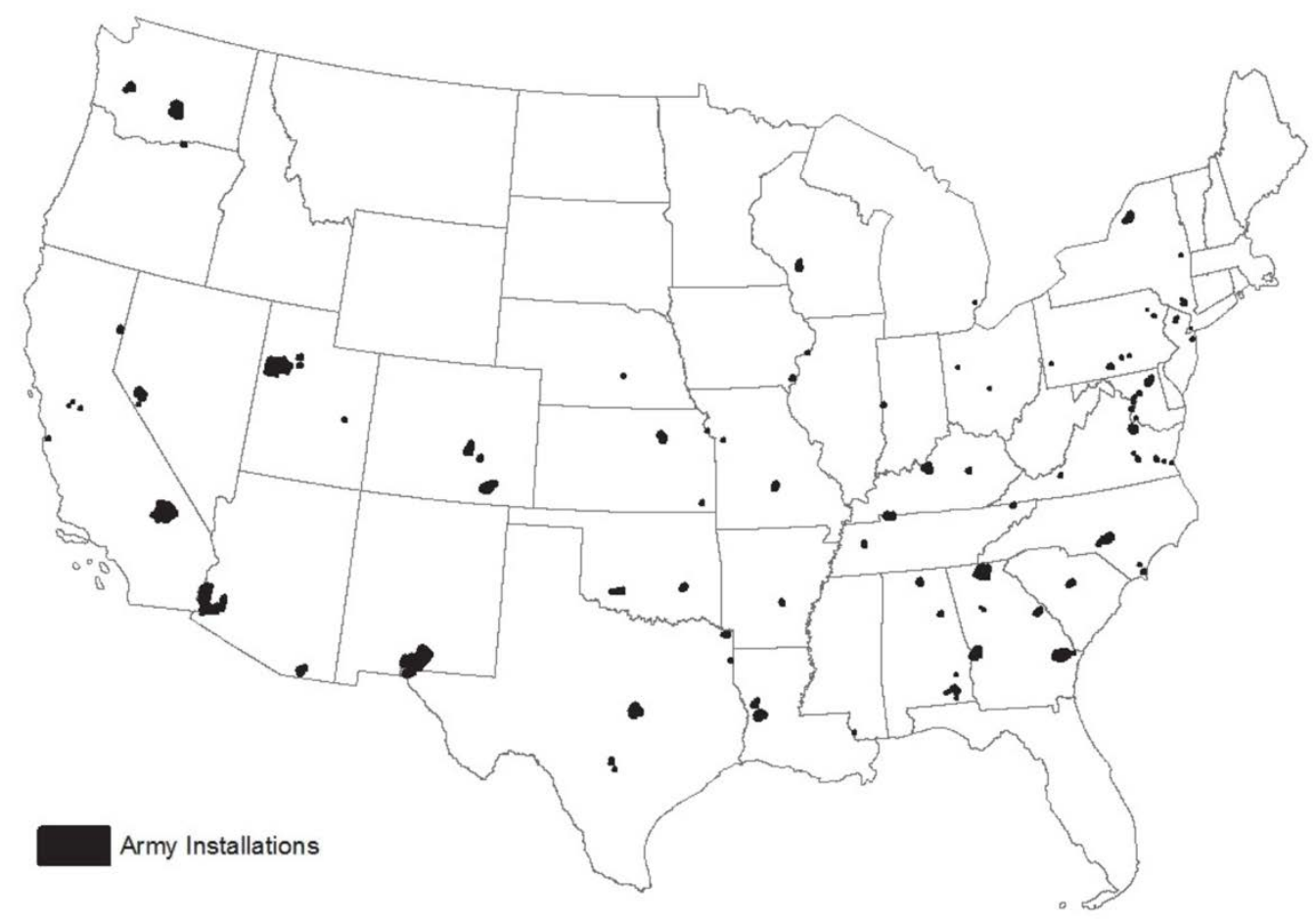

\subsection{Training area boundaries and buffers}

\subsubsection{Definition}

In order to implement the proposed change to the methodology for calculating the population impact MVA as described in Wilhoit et al. (2016), population density and growth rates must be calculated at varying buffer distances from the training area. The greatest impact of urban growth surrounding an installation results from growth near the training areas, not the cantonment area. This work used training-area boundaries, as opposed to installation boundaries, as the reference for buffering. For this work, distances of 1, 5, and 10 miles from training areas were buffered using the Training Areas Data set from the Sustainable Range Program (https:// srp.army.mil/). The goal was that, by using a variety of distances, 
it would be possible to weight the impact of development on the installation based on its proximity to the training areas. Because the footprint of the training area boundary is smaller than the installation boundary, the area included in the buffer is smaller.

The training areas data are very high resolution, with minor features where training cannot occur (such as streams) extracted from the middle of the training areas. This high resolution makes buffering very difficult because there are a large number of isolated slivers in the training area map, and the buffering tool within ArcGIS will crash. The present level of analysis does not require data at such high fidelity. Because the distances from the edge of a training area are the specific interest, RUG's Eliminate Polygon Part tool is used in the preprocessing model. Using the selected parameters, this tool eliminates small slivers in the training area map that are less than $1 \mathrm{~km}^{2}$. It does not have any impact on the outer boundary of the training areas, but significantly improves the processing time.

\subsubsection{Data source for training areas}

The training areas data set used in this report (Figure 3) originates from the Sustainable Range Program (https:// srp.army.mil/ ).

Figure 3. Map of the Army installations training areas data set.

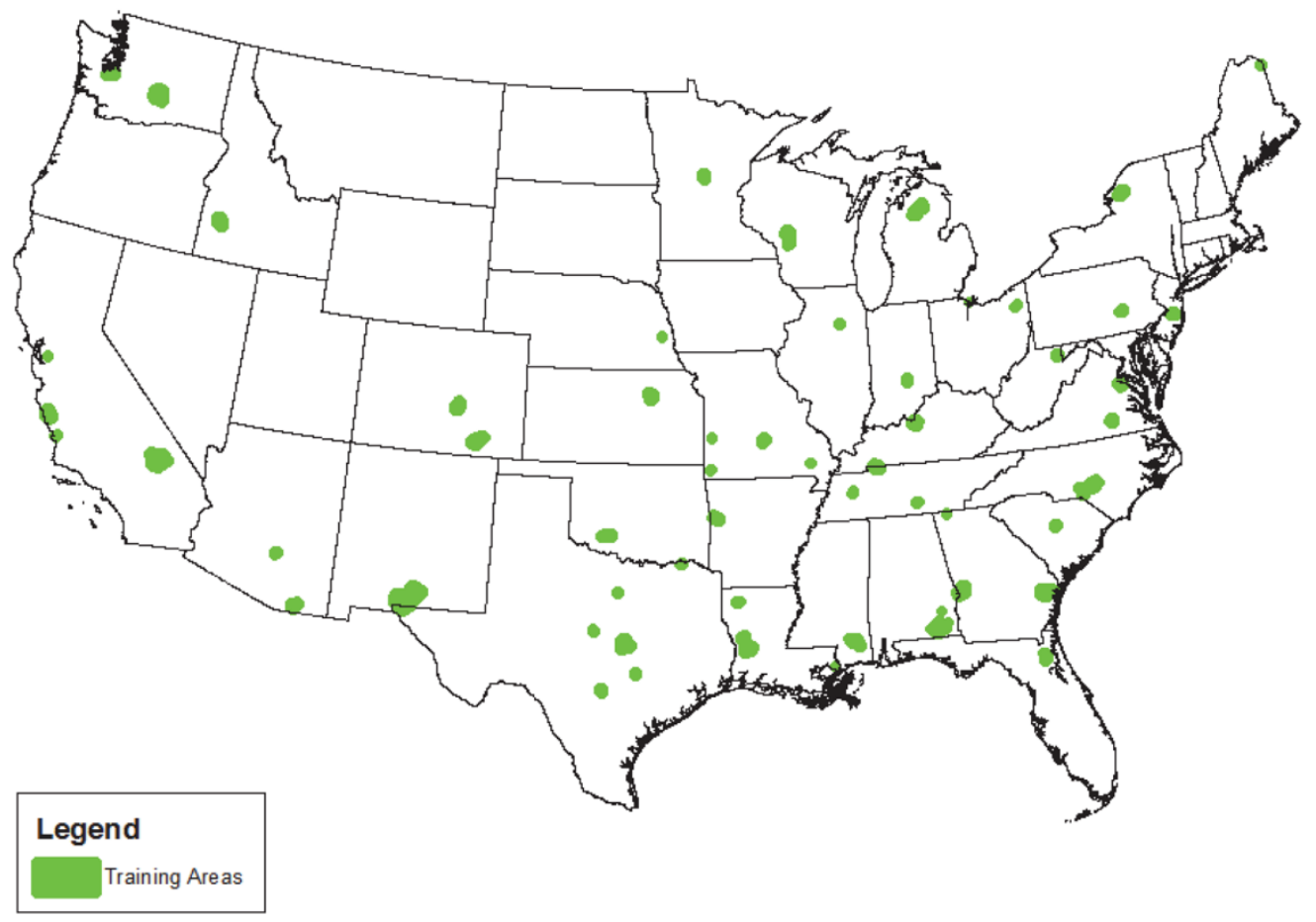




\subsection{Elevation}

\subsubsection{Data requirements and preparation}

Using the regional study area boundaries for each installation of interest, national elevation data from a raster digital elevation model (DEM) is clipped by the data-preparation tool to provide a DEM for each region in meters above sea level. The data-preparation tool outputs the DEMs in ASCII raster format. The DEM was used to calculate slope, which is one of the attractors considered in the RUG model. ERDC-CERL has a national scale DEM for all of CONUS that was utilized as input for the data preprocessing tool. However, if a national scale DEM is not available, individual DEM tiles can be downloaded for free from the national map viewer as described in section 3.4.2. Note that if individual tiles are downloaded, they must be mosaicked into a single DEM that provides complete coverage for all installations of interest prior to input to the data-preparation tool.

\subsubsection{Process for obtaining DEM}

The following steps describe how to obtain the required digital elevation data:

1. Navigate to the national map website (http:/ / viewer.nationalmap.gov).

2. Select "Download GIS Data" under the GIS data tab.

3. On the map screen check the "Use Map" box and the "Box/Point" button.

4. Click on upper left corner of area of interest on map and drag to lower right corner to identify area to download DEM that covers the study area of interest.

5. On the left screen under "Data", check "Elevation Products (3DEP)."

6. Check box next to the "1 arc-second DEM" and select "ArcGrid" under file format.

7. Click on the "Find Products" button. A list of all DEM tiles contained within the box that was drawn in step 4 will be listed.

8. Under the "Actions" column, click on "Download" for each tile you wish to download.

Alternately, if the user knows which 1 arc-second tiles are needed, complete tasks 1, 2, 5, and 6 above. Then, prior to step 7, click on "Advanced Search Options" and enter the tile grid number (e.g., n66w148). Next, click 
on the "Find Products" button. Note: a GIS intersect of the study area regions and the 1 arc-second DEM tile index feature class will provide a list of tiles that cover your study areas.

\subsection{Land cover}

\subsubsection{Data overview and preparation}

The National Land Cover Database (NLCD), developed by U.S. Geological Survey (USGS) Multi-Resolution Land Characteristics Consortium (MRLC), is a national raster data set of land cover in the United States. The National Land Cover Database characterizes land cover at 30 meter spatial resolution and has been calculated for 1992, 2001, 2006, and 2011. The National Land Cover Database exist for 2001 to 2011 and 2006 to 2011 and contains only those pixels that have changed between the two dates. All NLCD data products are available for free download from the MRLC.

Using the RUG data-preparation tool, the national NLCD map (Figure 4) and NLCD Change map are clipped to the study regions for all installations of interest and exported as ASCII raster files. The NLCD is used in RUG to identify locations which are attractive for development. For example, the land cover map is used to identify dense urban centers. These areas act as an attractor to urban growth as we presume that urban grown will generally happen in proximity to other urban growth. Additionally, the land cover map is also used to calculate distance to forest and distance to water, both of which are attractors in the model. The land cover map is used to identify areas where projected growth can occur, preventing development on certain types of land cover such as water and wetlands. Due to the processing algorithm used, the original NLCD land cover map has roads classified as urban. Within the RUG analysis, a roads mask is used to mask out the road category so that the only remaining urban land cover types are residential. 
Figure 4. Map of the CONUS National Land Cover Database layer.

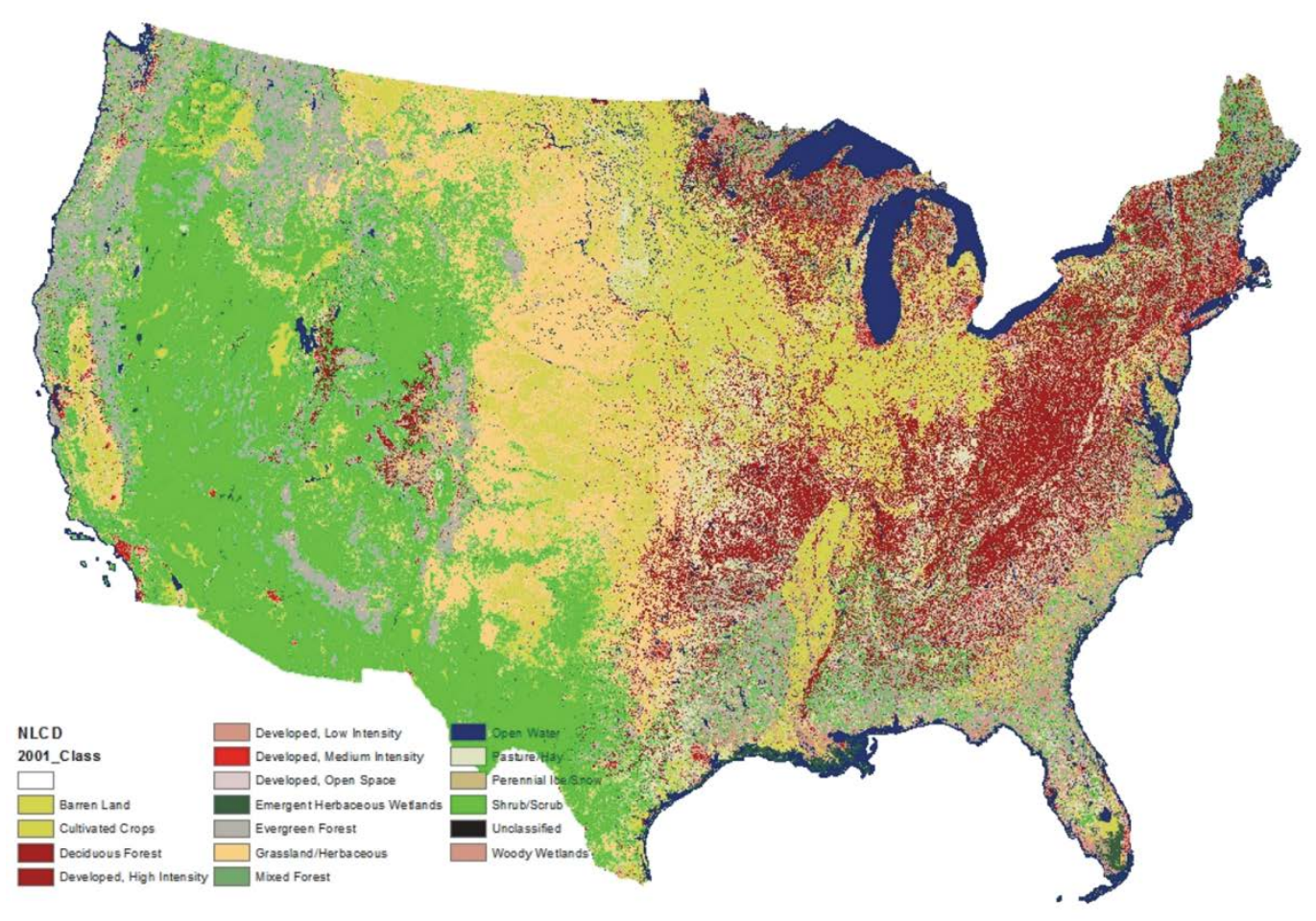

Furthermore, the NLCD change map is used for the training map, which is a raster map delineating where urban development has recently occurred. These developments were assumed to reflect the land's current attractiveness for development. This map is used to calibrate the equations used to calculate the attractiveness of every grid cell across the study area.

Additionally, the NLCD data were selected for the development of a factor of change/ development. There are many sources for these inputs and can range from a historic population growth percentage to population projections. Using those measures generally requires the calculations to be done at the county level. Since some of the counties around military installations (particularly in Alaska) are very large, we wanted to identify another way of calculating the parameter for growth. For example, there may be development in a far-off portion of a county that could be a considerable distance away from the installation and therefore have little effect on it. In conducting a national assessment, it is recommended that historical land cover data be used to estimate future regional growth, feeding annual percent growth into RUG. In this research, the NLCD map from 2011 and the NLCD change map from 2006 to 2011 were used to identify new areas of growth by applying the following algorithm: 


$$
A G R=\frac{T A_{\text {diff }} /\left(T A_{2011}-T A_{\text {diff }}\right)}{5}
$$

Eq. 1

where AGR is annual grouth rate, TAdiff, is the total area changed to land cover categories 22 or 23 between 2006 and 2011; and TA2011 is the total area of land cover categories 22 or 23 in 2011. Land cover category 22 is defined as Developed, Low Intensity; land cover category 23 is Developed, Medium Intensity.

\subsubsection{Exclusion of Hawaii}

The analysis outlined in this report is easily reproducible for any location in CONUS or Alaska. However, as this work began there was not a National Land Cover map available for the state of Hawaii, and so it was excluded. During the preparation of the final report, the research team found that a partner of the Multi-Resolution Land Characteristics Consortium (MRLC) - the Coastal Change Analysis Program (C-CAP) of the National Oceanic and Atmospheric Administration-had produced a land cover map of Hawaii. The C-CAP data conform to land cover classifications similar, but not identical to, those used in the NLCD. For the purposes of our analysis, these differences are acceptable and would not skew the methodology. To be able to run RUG for Hawaii, minor modifications to the script would be required to preprocess data for RUG.

\subsubsection{Obtaining NLCD}

Figure 5 shows the NLDC web user interface. The following steps describe how to obtain the NCLD:

1. Navigate to the Multi-Resolution Land Characteristics Consortium webpage (http:/ / www.mrlc.gov/ ). RUG requires Land Cover Characteristic data from two points in time to estimate change characteristics. The 2016 analysis conducted by ERDC/ CERL used data from 2006 and 2011. However, one should select the most recently published data.

2. Download data for the two most recent years. In this research, the NLCD 2011 Land Cover map and the NLCD 2006 to 2011 Land Cover Change map were used for analysis. 
Figure 5. Screen shot of the NLDC web-user interface

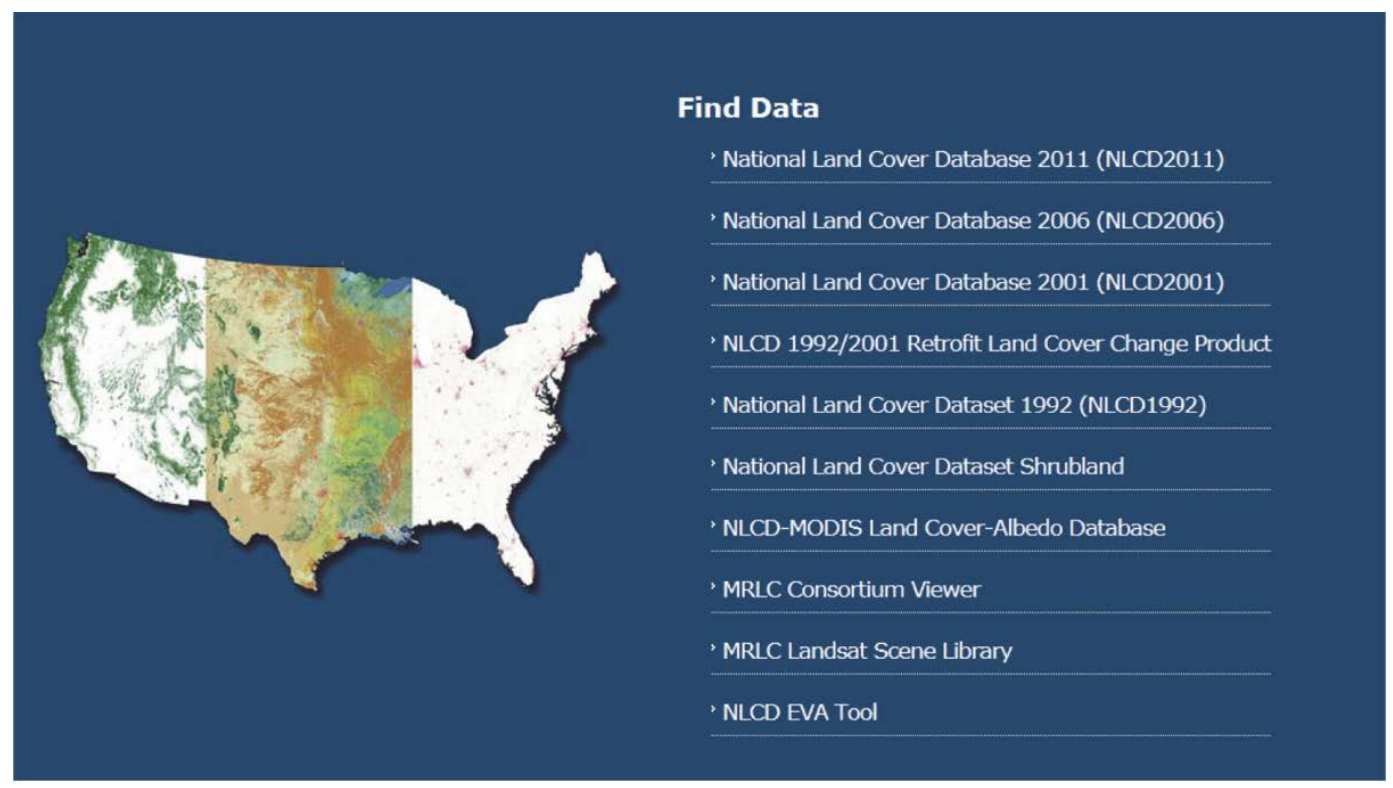

\subsection{Roads}

\subsubsection{Data overview}

A vector road network of Roads in the United States is available from the national map. In the data-preparation tool these roads are clipped to only include those in the study regions. Using the "ROAD_CLASS" field, the data-preparation tool reclassifies roads into "interstates" and "other roads". Both of these maps are then rasterized by the tool, producing ArcGIS ASCII grid files.

When the roads are used in RUG, travel times to various attractors (such as water and urban areas) are calculated based on assumptions for speeds based on the road classification held in the "ROAD_CLASS" field. Therefore, it was possible to distinguish between road types and to assign appropriate travel speeds for the different types of roads.

\subsubsection{Accessing road data}

1. Navigate to the national map website (http://viewer.nationalmap.gov/).

2. Select "Download GIS Data" under the GIS Data tab.

3. On the left screen under "DataSets" select Transportation $>$ National Transportation Dataset > Data Extent National (see Figure 6, next page)

4. Click on the "Find Products" button

5. Under the "Actions" column, click on "Download". 
Figure 6. Screenshot showing how to access the National Roads from the National Map Viewer.

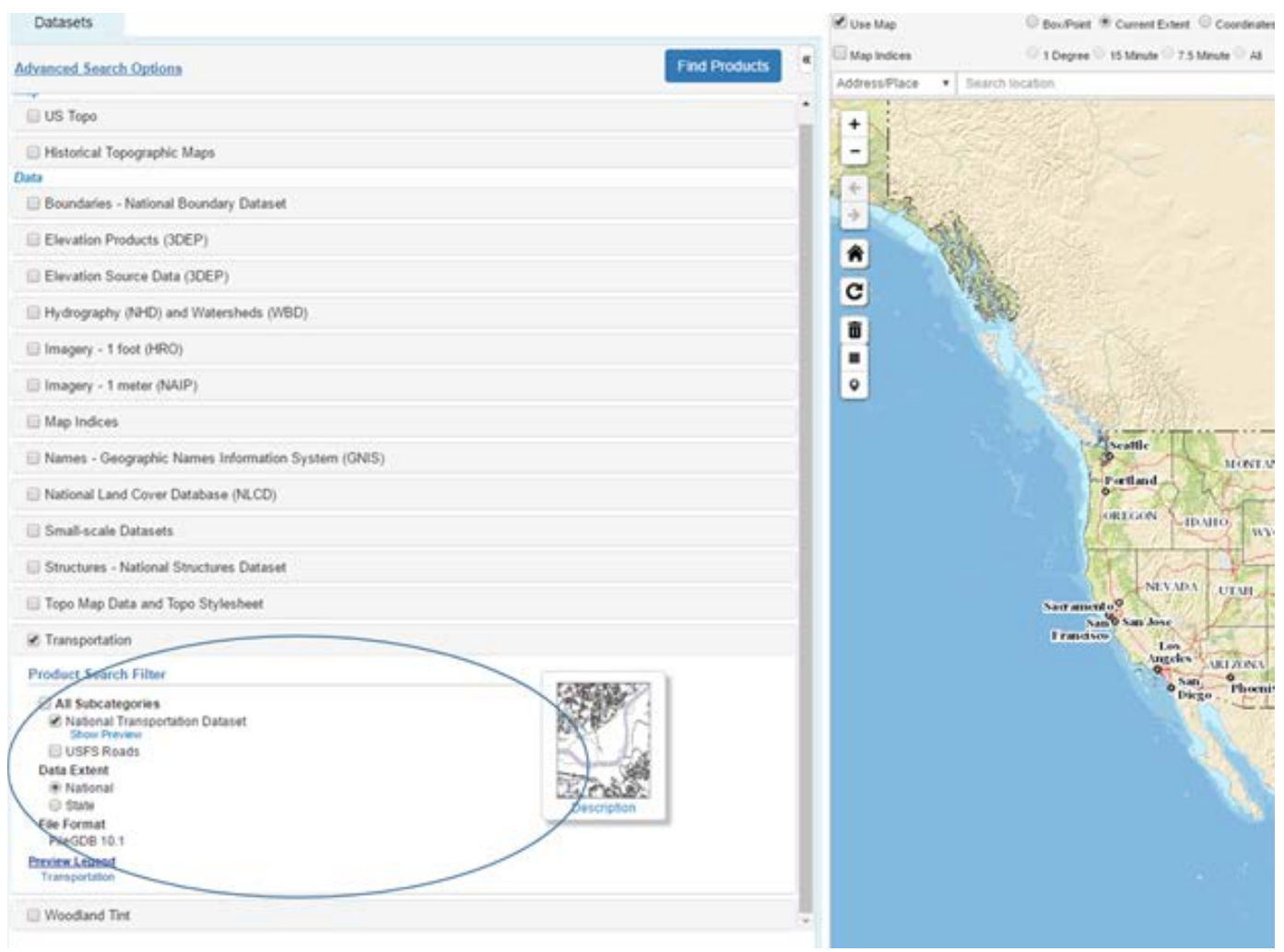

\subsection{Flood hazard layer}

\subsubsection{Data overview and preparation}

The national flood hazard layer is utilized by RUG to calculate how much projected future development might occur in flood hazard areas (see Figure 7). The data-preparation tool accepts an ArcGIS vector shapefile of national flood hazard areas and then clips out only flood hazard areas that occur within the installation study regions. The flood hazard map is then rasterized by the tool, producing an ArcGIS ASCII raster file where flood hazard areas are assigned a value of " 1 " and non-flood hazard areas are assigned a value of "no data". 
Figure 7. National flood hazard layer.

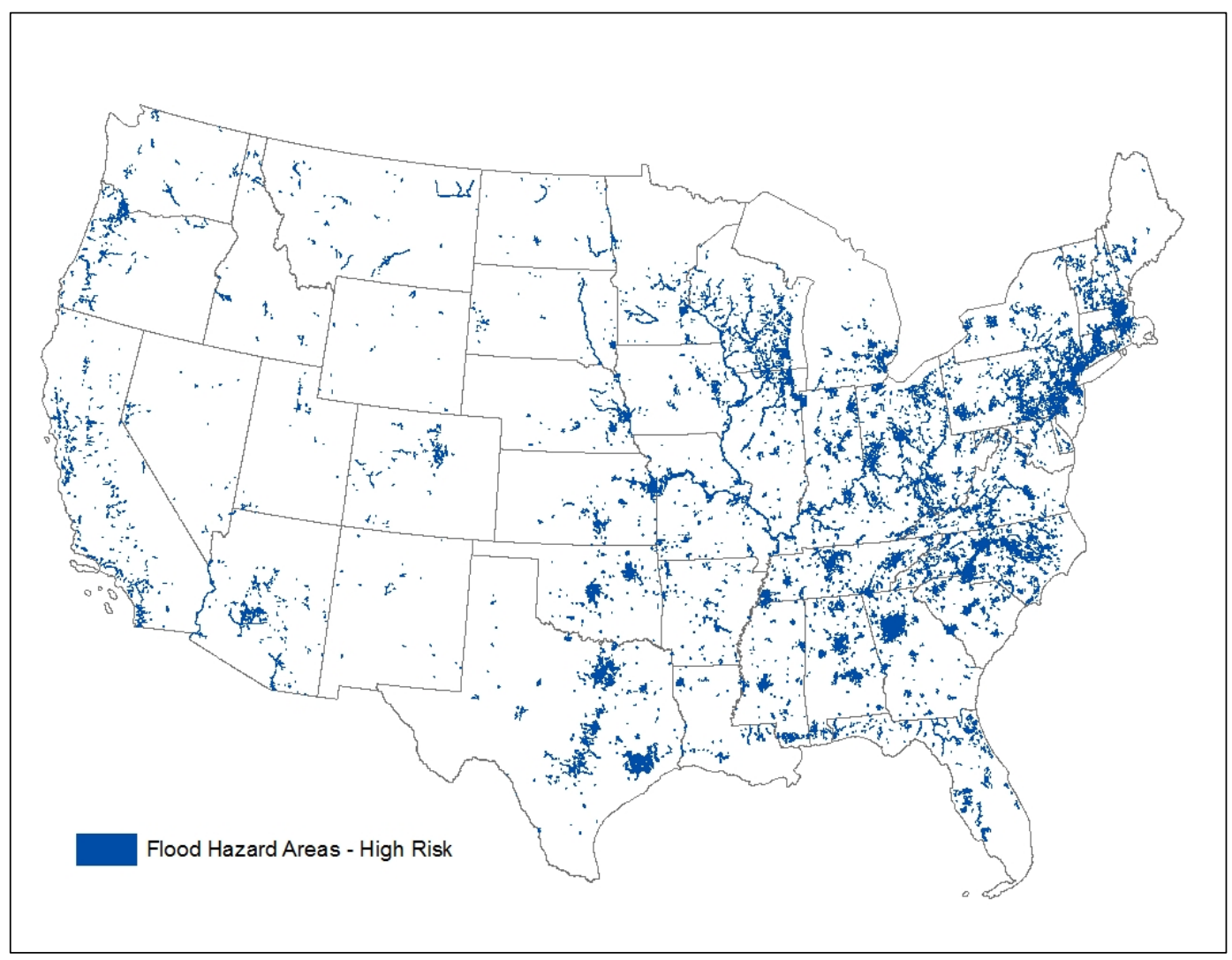

\subsubsection{Accessing the national flood hazard layer}

The data are available through the Homeland Security Infrastructure Program (HSIP) which is managed by the Homeland Infrastructure Foundation-Level Data (HIFLD). Federal government employees and contractors can access the data by contacting the HIFLD Support Team at HIFLD@hq.dhs.gov or by visiting https:// hifld-dhsgii.opendata.arcgis.com/.

\subsection{Protected areas}

\subsubsection{Data overview}

An important part of the RUG model is identification of the areas where growth cannot occur. This requires two data sources. One is the Protected Areas and the other is the Army Compatible Use Buffer (ACUB) boundaries (see section 3.9 for the latter). These two sources are combined into a raster file. The Protected Areas Database is available at no cost as a download by state from the National Gap Analysis Program/ Protected Areas Data Portal. Protected areas that are delineated in this data set (see Figure 
8) represent any type of land where development would not be permitted, such as federal or state owned land, parks, natural areas, wetlands, and military installations.

Figure 8. Protected areas data set.

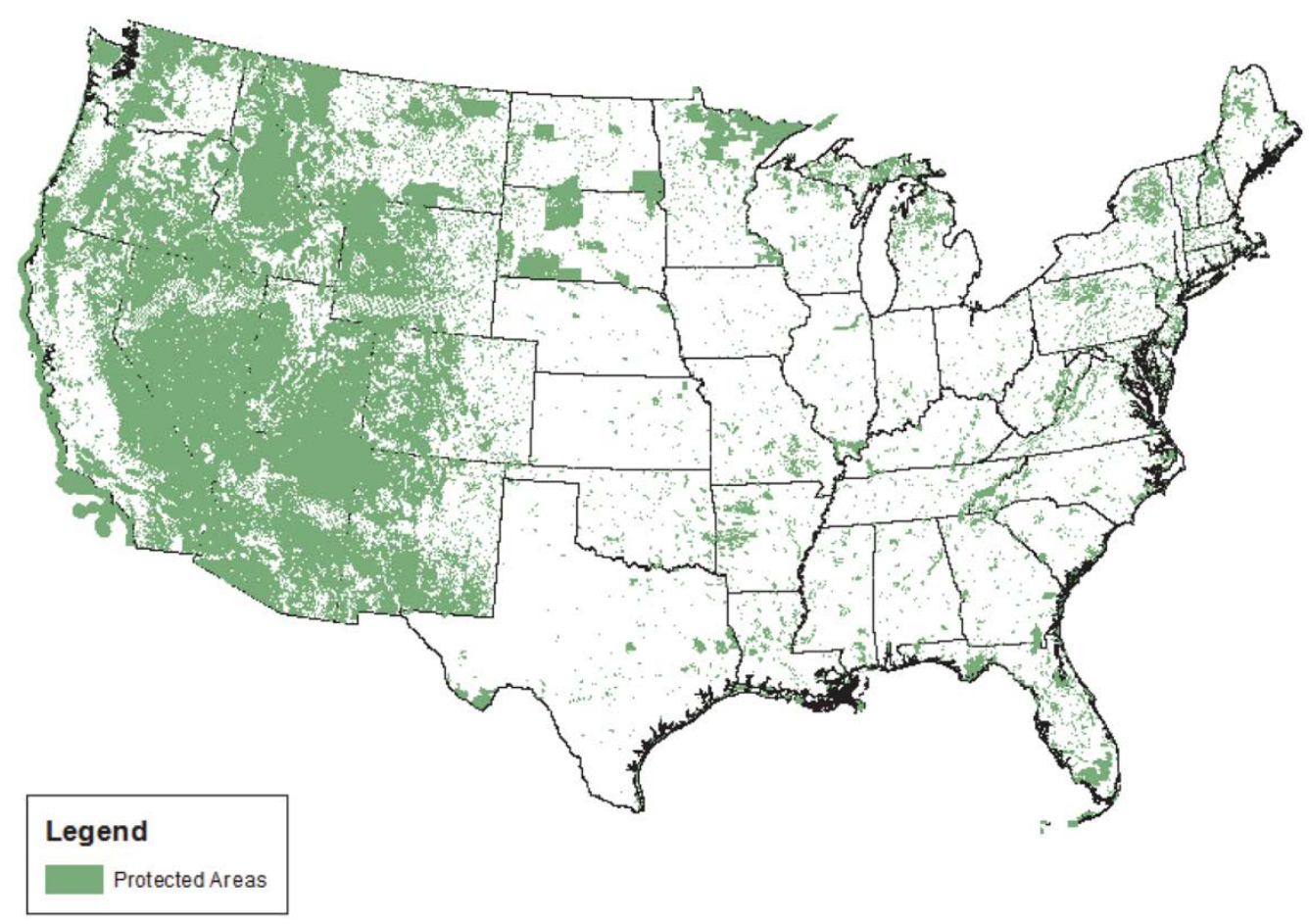

In the data-preparation tool, protected areas are clipped to only include those in the study regions. Protected areas are merged with ACUB areas as described in section 3.9.

\subsubsection{Obtaining protected areas data set}

These data can be acquired as follows:

1. Navigate to the National Gap Analysis Program's data download page at http:/ / gapanalysis.usgs.gov/ padus/ data/ download/ .

2. Select to download the "Protected Areas Database (PAD-US)" as an ArcGIS v.10 geodatabase (see Figure 9). 
Figure 9. PAD-US download page showing correct selections.

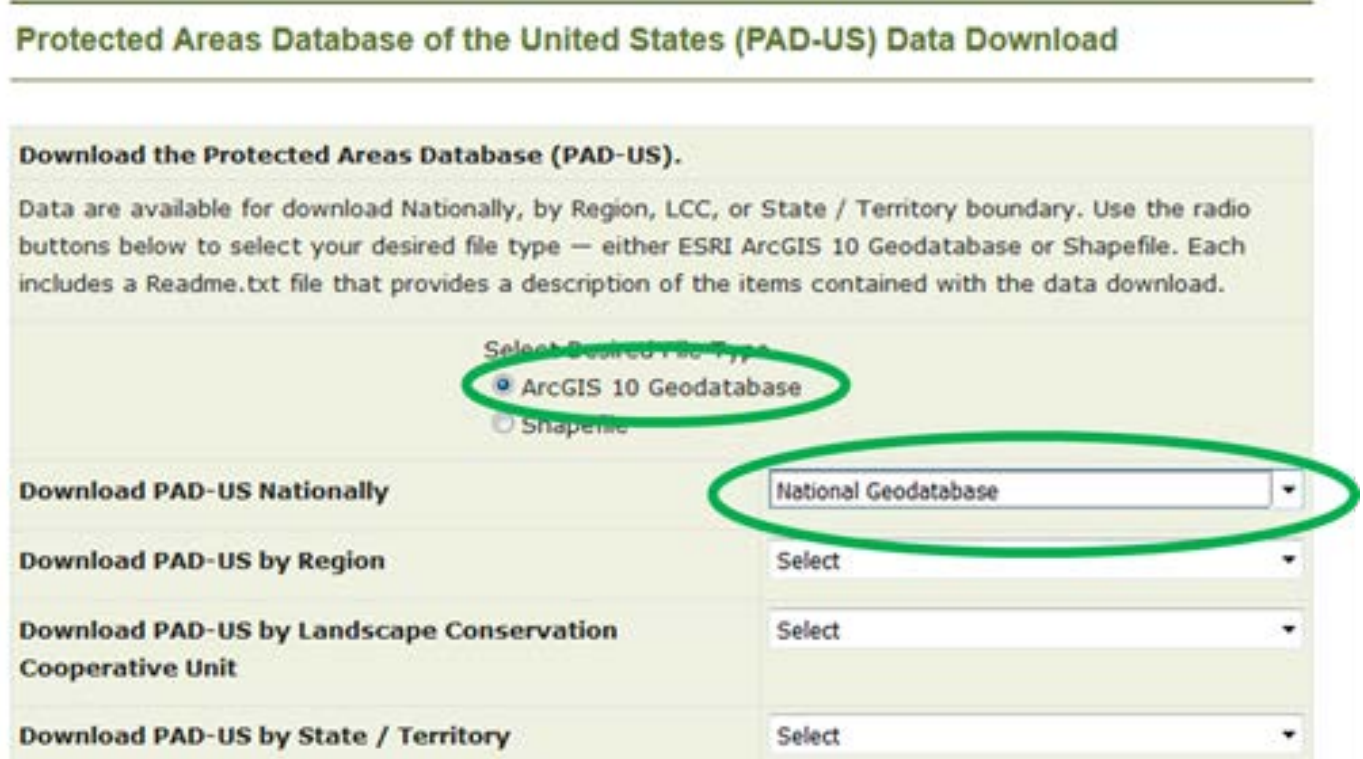

\subsection{Army Compatible Use Buffer (ACUB)}

\subsubsection{ACUB overview}

The second source of data used to compile the NoGrowth map was the boundary of Army Compatible Use Buffer (ACUB) areas in the vicinity of installations. The ACUB program is a tool used to protect an installation's accessibility, availability, and capability for training, testing, and operations by sustaining natural habitats, open space, working lands, cultural resources, and communities. ACUB land-development right acquisitions generally work through cooperative agreements that place restrictions on the development of land outside of an installation boundary. Managed by the U.S. Army Environmental Command (USAEC), a subcommand of the Installation Management Command (IMCOM), the ACUB program supports soldier combat readiness training through partnerships with public and private landowners and organizations. ACUB data were obtained from the USAEC ACUB team and combined with the Protected Areas Database to produce an ArcGIS vector shapefile of a NoGrowth map within all of the installation study regions. The data-preparation tool then rasterizes the map, resulting in an AroGIS ASCII raster file where areas where growth is prohibited were assigned a value of " 1 " and background areas where growth was possible were assigned a value of "no data." 


\subsubsection{Obtaining ACUB data}

Currently there is no national data set for ACUB lands. Individual installations with ACUB programs share the data on their lands annually with the U.S. Army Environmental Command ACUB team. To obtain the most recent data this team should be contacted for shapefiles of the ACUB boundaries. The boundary files are updated annually. More information about the program and obtain the most current contact information is available at http://www.aec.army.mil/Services/Conserve/ArmyCompatibleUseBufferProgram.aspx.

\subsection{Population estimates from LandScan}

\subsubsection{Population data overview}

Population data for a given region were obtained from LandScan ${ }^{\mathrm{TM}}$ U.S. population estimates developed by Oak Ridge National Laboratory (Figure 10). Using U.S. census data, satellite imagery, nighttime lights, and other factors, LandScan provides population estimates for 60 x 60 meter cells. In the data-preparation model, this raster file was clipped to regional extent. The population estimate information contained in the raster files is used for calculating present population density in the post-processing model.

Figure 10. CONUS population estimates from derived from LandScan.

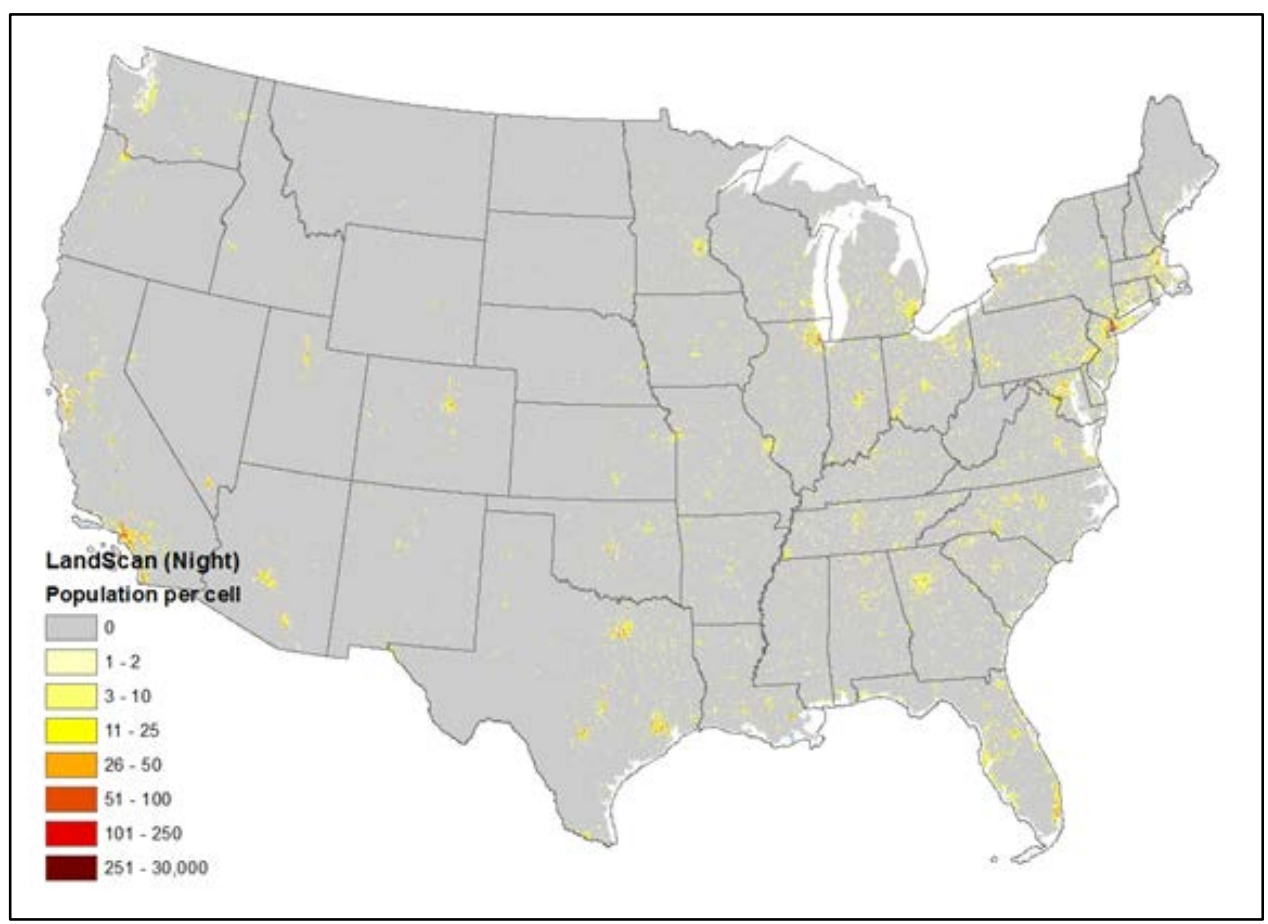


To produce the estimates, LandScan apportions census counts to grid cells based on likelihood coefficients, which are based on proximity to roads, slope, land cover, nighttime lights, and other information (ORNL 2015). We recommend the use of night estimates on the assumption that most people will be in their place of residence at night, and that can account for the encroachment factor of light pollution. Because the data are available at a scale finer than census blocks and are updated annually, population estimates can confidently be prepared at a smaller scale.

\subsubsection{Obtaining the data}

LandScan data are available free of charge for U.S. federal government agencies. Due to changes in data access, registration for the data set will begin when you send an email to LandScanRegister@ornl.gov and make a request to register for the latest available LandScan data. The data will be mailed via a DVD.

\subsection{Preparing the data in ArcMap}

Once the data has been gathered, it needs to be made readable in RUG model. As part of this research effort we developed a data-preparation tool using Model Builder in ArcGIS for Desktop Advanced 10.2.2. First, add the data-processing toolbox to ArcMap. ArcMap is a powerful mapping (GIS) software which has over 15,000 copies in use across the United States Army. Users without an ArcGIS license can obtain a free 60-day trial from ESRI (http://www.esri.com/software/arcgis/arcgis-for-desktop/free-trial). Some common troubleshooting issues are discussed in Appendix C.

The tool takes the necessary data sources described in this chapter and processes them into the format required to run RUG. More specifically, the tool accepts national-scale geospatial data as input, rasterizes vector data, reclassifies raster data as necessary, completes two different buffering functions, clips all data sets to a common study area region while ensuring that each raster layer has the same spatial resolution and number of rows and columns of pixels, and exports results to an ArcGIS ASCII grid format. In this research, all data layers were processed to produce an output with a 30 meter spatial resolution.

The processed data are output in a unified manner that RUG can read. The user specifies an output location in the data-preparation tool. Within that folder the data-preparation tool creates a subfolder for each installation 
and places the related data in that folder. For detailed information on how to use ArcMap to run the data processing tool, please see ArcMap tips and tricks located in Appendix D.

\subsubsection{Project data}

To reduce processing time, the ArcGIS tool assumes that all data are in the same projection. For CONUS this is USA Contiguous Albers Equal Area Conic USGS version (WKID: 102039 ) and for Alaska this is NAD 1983 Alaska Albers (WKID:3338). An equal area projection was selected because the assessment focuses on measuring the area of new development within certain mile buffers of an installation. By having the input data sets pre-projected, if the tool fails (or needs to be rerun), processing time will be reduced because this operation does not have to be repeated. If the intent is to analyze both Alaska and CONUS installations, the datapreparation tool should be run separately for the Alaska installations since they are in a different projection and therefore require a different set of input data. To assist in the projecting process, a tool was developed to project the data. The user interface is shown in Figure 11. 
Figure 11. Screen shot of the Population Impact Data Processing Model developed for ArcMap which prepares data sets for use in RUG.

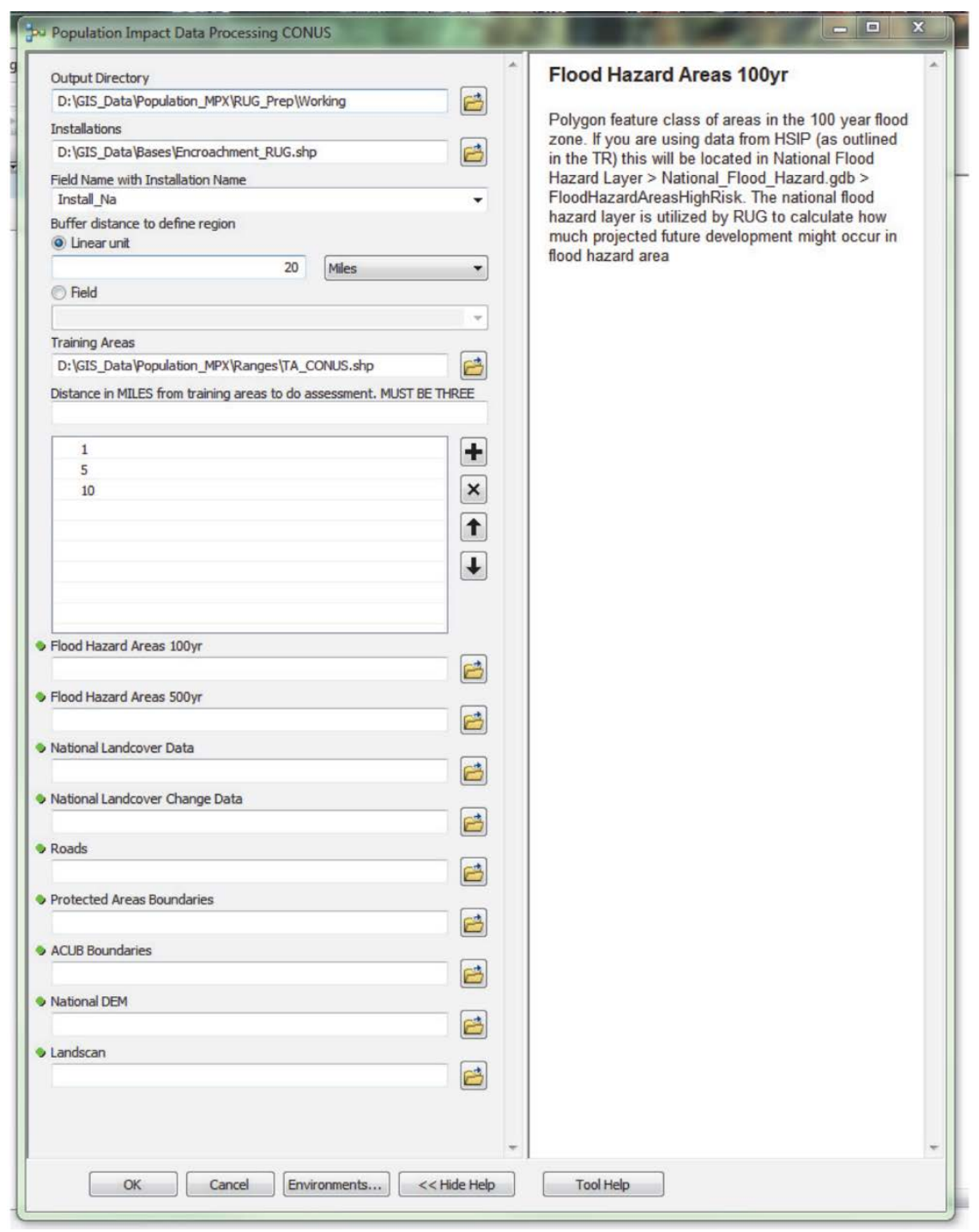

\subsubsection{Run the data-preparation model}

Using the pre-projected data the user can run the custom ArcGIS datapreparation model from ArcMap, which is shown in Figure 12. The data will be clipped to fit the boundary of the region and placed in a folder for each installation within the output directory. Table 1, below, provides additional information on the data required for each of the options in ArcMap. 
Figure 12. Results produced by RUG shown in ArcCatalog window prior to MVA tool being run.

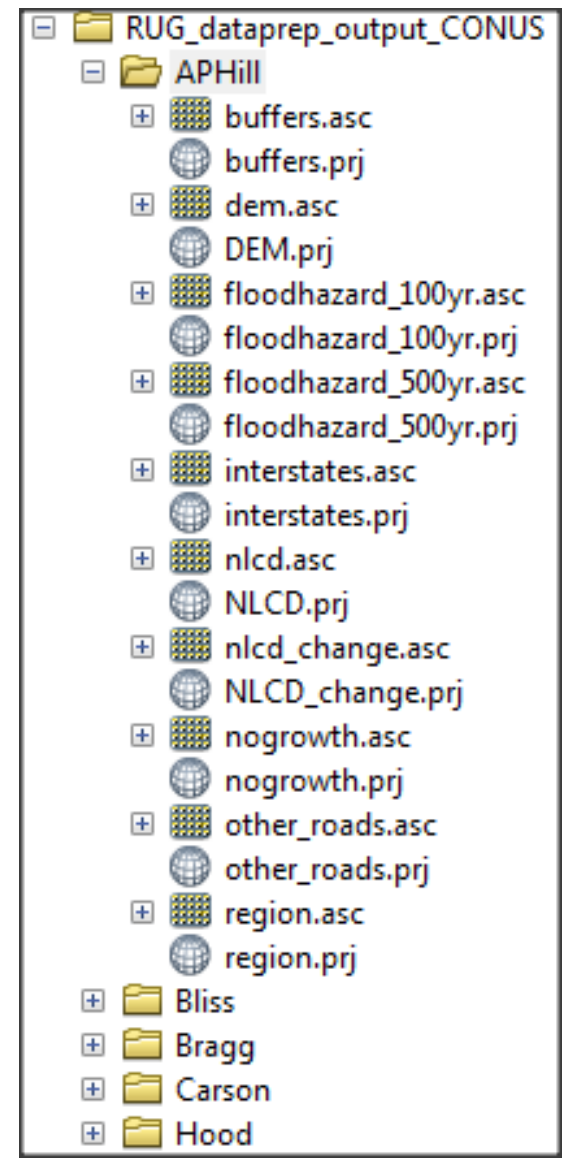

Table 1. Summary of the inputs required for the preprocessing model.

\begin{tabular}{|l|l|l|}
\hline \multicolumn{1}{|c|}{ Parameter } & Explanation & Data Type \\
\hline Output Directory & $\begin{array}{l}\text { Folder where you would like to have the output files written to. Within this folder a } \\
\text { sub-folder will be created for each installation. }\end{array}$ & Folder \\
\hline Installations & $\begin{array}{l}\text { POLYGON feature class of Army Installations to be analyzed. As this methodology is } \\
\text { being developed to assess encroachment surrounding Army installations, the } \\
\text { location of Army installations is an important starting point. The Army installation's } \\
\text { location will then determine the region and the extent of the analysis which is to be } \\
\text { conducted. }\end{array}$ & $\begin{array}{l}\text { Feature } \\
\text { Class }\end{array}$ \\
\hline $\begin{array}{l}\text { Field Name with } \\
\text { Installation Name }\end{array}$ & $\begin{array}{l}\text { Field name within the Installations feature class which contains the name of the } \\
\text { Installation. }\end{array}$ & Field \\
\hline $\begin{array}{l}\text { Buffer distance to } \\
\text { define region }\end{array}$ & $\begin{array}{l}\text { This number will define the region for all of the analysis. This will be the extent for } \\
\text { which population is distributed when the RUG is run. This must be greater than the } \\
\text { buffer distances. }\end{array}$ & $\begin{array}{l}\text { Linear unit } \\
\text { or Field }\end{array}$ \\
\hline Training Areas & $\begin{array}{l}\text { Polygon feature class of the training area boundaries. From these training areas a } \\
\text { buffer (below) will be applied to define the regions of analysis. }\end{array}$ & Shapefile \\
\hline
\end{tabular}




\begin{tabular}{|c|c|c|}
\hline Parameter & Explanation & Data Type \\
\hline $\begin{array}{l}\text { Distance in MILES } \\
\text { from training areas to } \\
\text { do assessment MUST } \\
\text { BE THREE }\end{array}$ & $\begin{array}{l}\text { The distance from the training areas which you would like to do the assessment. } \\
\text { Population density and growth rates need to be calculated at varying buffer } \\
\text { distances from the training area. As the greatest impact of urban growth } \\
\text { surrounding an installation results from growth near the training areas, as opposed } \\
\text { to near the cantonment area, this work proposes using training area boundaries } \\
\text { as opposed to installation boundaries as the buffering point. In the results } \\
\text { presented in this report, distances of, 1, 5, and } 10 \text { miles from training areas were } \\
\text { buffered using the Training Areas Dataset from the Sustainable Range Program. }\end{array}$ & $\begin{array}{l}\text { Multiple } \\
\text { Value }\end{array}$ \\
\hline $\begin{array}{l}\text { Flood Hazard Areas } \\
\text { 100yr }\end{array}$ & $\begin{array}{l}\text { Polygon feature class of areas in the } 100 \text { year flood zone. If you are using data } \\
\text { from HSIP (as outlined in the TR) this will be located in National Flood Hazard Layer } \\
\text { > National_Flood_Hazard.gdb > FloodHazardAreasHighRisk. The national flood } \\
\text { hazard layer is utilized by RUG to calculate how much projected future } \\
\text { development might occur in flood hazard area. }\end{array}$ & $\begin{array}{l}\text { Feature } \\
\text { Class }\end{array}$ \\
\hline $\begin{array}{l}\text { Flood Hazard Areas } \\
500 y r\end{array}$ & $\begin{array}{l}\text { Polygon feature class of areas in the } 500 \text { year flood zone. If you are using data } \\
\text { from HSIP (as outlined in the TR) this will be located in National Flood Hazard Layer } \\
>\text { National_Flood_Hazard.gdb > FloodHazardAreasModtoLowRisk. The national } \\
\text { flood hazard layer is utilized by RUG to calculate how much projected future } \\
\text { development might occur in flood hazard areas. }\end{array}$ & $\begin{array}{l}\text { Feature } \\
\text { Class }\end{array}$ \\
\hline $\begin{array}{l}\text { National Land cover } \\
\text { Data }\end{array}$ & $\begin{array}{l}\text { The National Land Cover Database (NLCD), developed by United States Geological } \\
\text { Survey's Multi-Resolution Land Characteristics Consortium (MRLC), is a national } \\
\text { raster map of land cover in the United States. There are many options for NLCD } \\
\text { data. For this data set you want to select one static year (2011?). }\end{array}$ & $\begin{array}{l}\text { Composite } \\
\text { Geodataset }\end{array}$ \\
\hline $\begin{array}{l}\text { National Land cover } \\
\text { Change Data }\end{array}$ & $\begin{array}{l}\text { The National Land Cover Database (NLCD), developed by United States Geological } \\
\text { Survey's Multi-Resolution Land Characteristics Consortium (MRLC), is a national } \\
\text { raster map of land cover in the United States. There are many options for NLCD } \\
\text { data. For this data set you want to select the data set which contains "from year to } \\
\text { year" in the file name. }\end{array}$ & $\begin{array}{l}\text { Composite } \\
\text { Geodataset }\end{array}$ \\
\hline Roads & Line feature class of roads. This must be obtained from the National Map. & $\begin{array}{l}\text { Feature } \\
\text { Layer }\end{array}$ \\
\hline $\begin{array}{l}\text { Protected Areas } \\
\text { Boundaries }\end{array}$ & $\begin{array}{l}\text { Polygon feature class from the National Gap Analysis Program/Protected Areas } \\
\text { Data Portal. }\end{array}$ & $\begin{array}{l}\text { Feature } \\
\text { Layer }\end{array}$ \\
\hline ACUB Boundaries & $\begin{array}{l}\text { Boundaries for Army Compatible Use Buffer (ACUB) programs. This needs to be } \\
\text { obtained from the U.S. Army Environmental Command ACUB Team. If there are no } \\
\text { ACUB boundaries for the installations to be looked at, then select an empty } \\
\text { shapefile. }\end{array}$ & Shapefile \\
\hline National DEM & Select the raster digital elevation model. & $\begin{array}{l}\text { Composite } \\
\text { Geodataset }\end{array}$ \\
\hline Landscan & $\begin{array}{l}\text { To obtain current estimations of population in a region, we obtained population } \\
\text { estimates from LandScan }{ }^{\mathrm{TM}} \text { U.S. population estimates developed by Oak Ridge } \\
\text { Laboratory. Select the night estimates. }\end{array}$ & $\begin{array}{l}\text { Composite } \\
\text { Geodataset }\end{array}$ \\
\hline
\end{tabular}




\section{Running RUG}

Once the data are prepared in the data-preparation model, RUG is ready to run. The user interface is shown in Figure 13. The model places patterns of urban growth over a user-specified time interval, producing a basis for a potential land cover map for some future date. This is accomplished by calculating the number of new growth locations needed, identifying the grid cells that could be developed, and then creating a sorted list of those locations based on attractiveness. Attractiveness for each grid cell was based on the attractiveness value in the input map and the amount of randomness (see randomness coefficient below) specified by the user, which for this project was set to the minimum. The random-factor accounts for randomness in decision making, and for the fact that a knowledge of past growth patterns is not a full predictor of future growth. The top grid cell in the list is then developed, followed by the second most attractive, followed by the third, and so on. Depending on whether the neighborhood size coefficient is set, ${ }^{*}$ either the adjacent grid cells are developed to create a neighborhood up to a specified size, or the grid cell with the next highest attractiveness value is developed without considering adjacency to the previously developed patch. This process is continues until the simulation time frame is completed (Westervelt, BenDor, and Sexton 2011).

Figure 13. Graphical user interface for RUG.

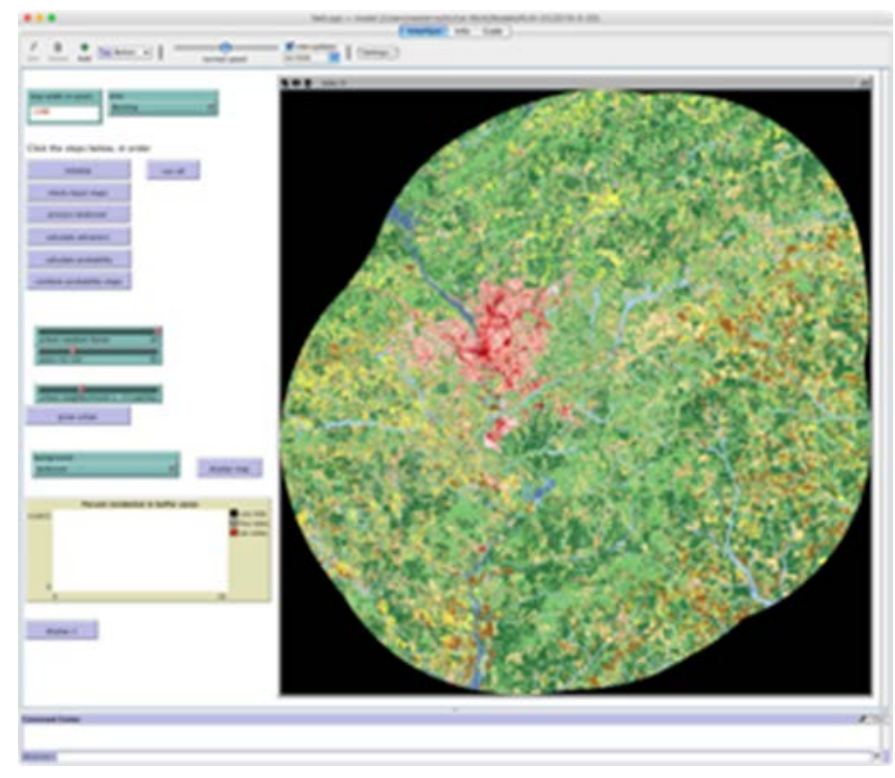

${ }^{*}$ Also see section 4.2.3. 


\subsection{Configuring RUG}

Download and install NetLogo, a free J ava-based multi-agent programming environment developed and maintained at the Northwestern University Center for Connected Learning and Computer-Based Modeling (CCL). NetLogo can be downloaded from https:// ccl.northwestern.edu/netlogo/.

A portion of the RUG analysis occurs within the open source statistical programming language $\mathrm{R}$. The most current version of $\mathrm{R}$ is available at https:// www.r-project.org/.

The free NetLogo- $R$ extension is required to enable NetLogo and $R$ to interface and communicate. The package and installation information are available at http://r-ext.sourceforge.net/.

\subsection{RUG input parameters}

\subsubsection{File location}

The output files from the ArcGIS data-preparation model are, by default, saved in a particular data structure within a user-specified folder. You must provide the RUG model with the output directory you selected in the data-preparation model.

\subsubsection{Runtime}

The user must specify the number of years to run the simulation. In this project, the simulation was run for 30 years. Thirty years was selected based on professional opinion of how long into the future the model results are useful before construction of new roads make the model results inaccurate.

\subsubsection{Neighborhood size}

The neighborhood size coefficient determines how dispersed or clustered the projected new urban growth pixels should be in the resulting land cover map. This value was set to zero in the analysis described in Wilhoit et al. 2016, allowing projected growth to be allocated to isolated pixels rather than forcing new development to occur in clusters or neighborhoods of pixels. However, to improve the analysis, a list of all of the neighborhood sizes of "clumps" of pixels identified as changed in the NLCD change 
map was compiled. Using this list, a neighborhood size coefficient was randomly selected each time that projected urban growth pixels were added to the map.

\subsubsection{Random-factor}

A coefficient denoting the weight of random or spontaneous growth. In this project, the randomness factor was set to the minimum possible value of $1 \%$, which specified that urban development was allocated to grid cells in the order of their calculated attractiveness to growth with a small (1\%) amount of randomness factored into the allocation. The random-factor accounts for the element of human choice, which impacts how development occurs. 


\section{Processing RUG Results to Create a Population Impact MVA}

An ArcGIS tool was developed to summarize the results and produce an MVA score for population impact. The MVA is the sum of population density and growth rates for each of the buffer distances. Each value is normalized on a scale of $0-n$, and the sum of $n$ must equal 10 . The MVA calculation is diagrammed in Figure 14. Because of the normalization required, NetLogo could not be utilized and the data had to be processed externally.

Figure 14. Graphic representation of MVA calculation.

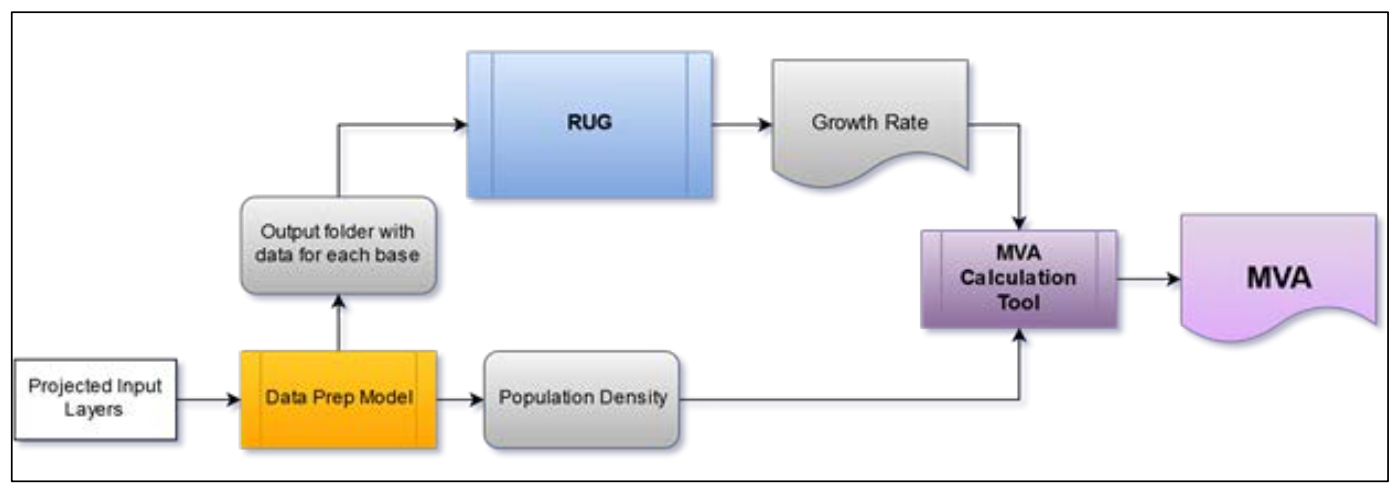

\subsection{Attribute weights}

The current CAA methodology assigns a weight of " 9 " to the population density and weight of " 1 " to the growth rate. Assessment done in the initial attribute creation by AEC found that there was little impact on the overall score by shifting the weights given to population density and growth rate. However, the present research determined that there were significant changes in scores depending on whether population density or growth rates were assigned more weight. Furthermore, it was found that the weighting of buffers had the largest impact on shifting the score of an installation.

Subject matter experts (SMEs) and key stakeholders should continue to be involved in the development of attribute weights. This methodology and the accompanying tool has been developed to be flexible so it can accommodate information provided by SMEs. Table 2 summarizes proposed Population Impact MVA weights based on the results of the present study. 
Table 2. Proposed Population Impact MVA weights.

\begin{tabular}{|ll|l|}
\hline Density Attribute Weights & Growth Attribute Weights \\
\hline 10-mile Population Density: & 2 & 10-mile Growth Rate: 2 \\
\hline 5-mile Population Density: & 1 & 5-mile Growth Rate: 1 \\
\hline 1-mile Population Density: & 2 & 1-mile Growth Rate: 2. \\
\hline
\end{tabular}

\subsection{RUG Results folder}

RUG outputs its results as .txt and .csv files within a folder labeled "results". This folder, shown in Figure 15, contains four files:

- annual-growth.txt: This is the growth rate used in RUG to produce estimations of future development. This figure is based on development trends between 2006- 2011 in the NLCD change map.

- equation.txt: These are the regression coefficients from the running of RUG.

- results.png: This is an image which demonstrates the new development after the model is run. The black indicates development which is projected through RUG while red areas are the training areas of new growth from 2006 to 2011 identified using NLCD.

- pct_low_density_urban_in_buffers.csv: This file contains the sum of the low density development within the specified mile buffer from training areas in each year. This file will be used in generating the MVA output.

Figure 15. Demonstration of the results folder and its contents after running RUG.

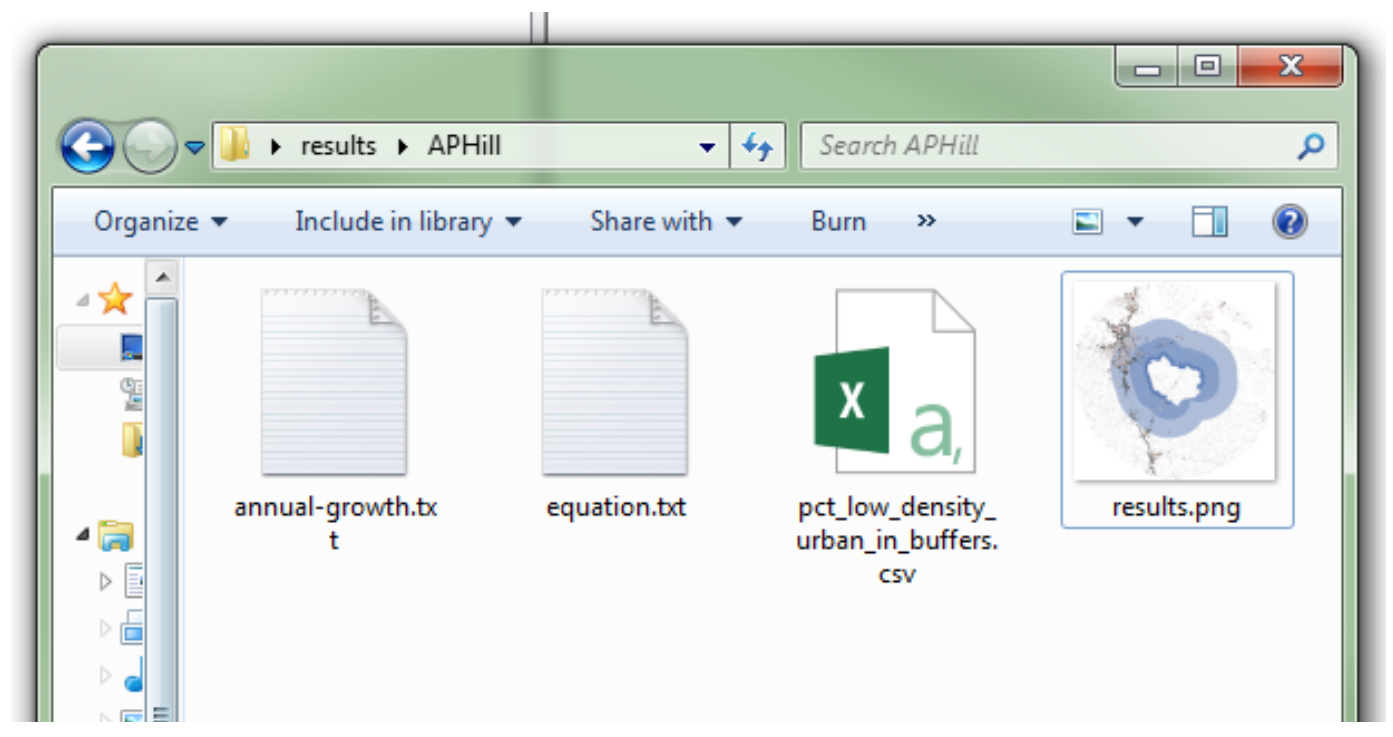




\subsection{Create Workspace folder}

Due to an error in the ESRI Model Builder software, there must be a folder called "Workspace" containing an empty file called "pct low_density_urban_in_buffers.csv" for the post-processing tool to work (see Figure 16). As a work around, a tool was developed which creates this workspace folder and an empty csv. The only parameter is Results Folder which is the location for the folder with the results from the RUG runs.

Figure 16. Screen shot of the Create Workspace tool.

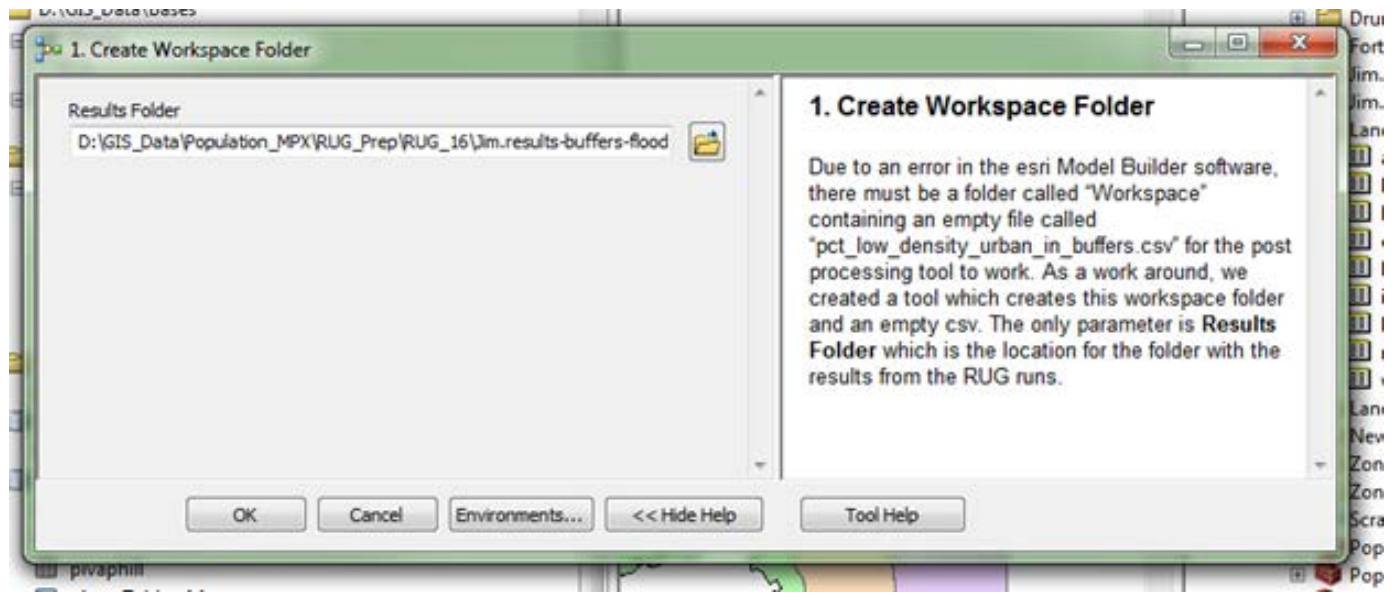

Failing to run this tool before executing the main processing model will produce an error such as the one shown in Figure 17. 
Figure 17. Common error message received when workspace folder is not created before running the MVA calculation tool.

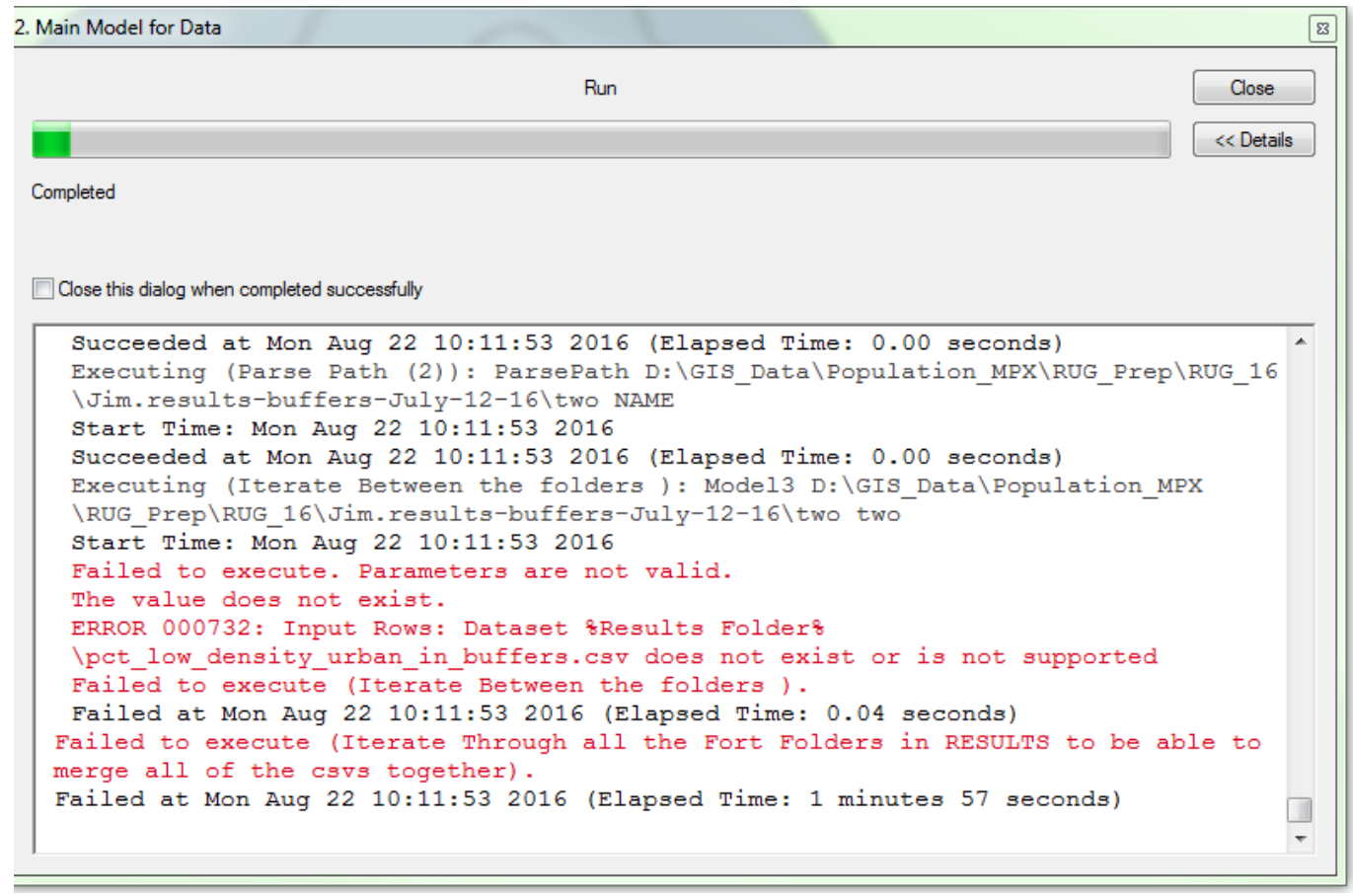

\subsection{Calculate MVA}

To produce an MVA score, run the following tool: "2. Post Process data from RUG for MVA." Using the outputs of the preprocessing model and RUG, this model calculates population density and the grouth rate for each installation and then creates a score from 0-10 indicating the risk of encroachment at an installation. The output is an Excel file that is placed in the results folder. The model receives two input folders which contain information for each installation: Summarized population estimates from LandScan (produced in the preprocessing model) and RUG output Results containing the amount of projected urban development. The script iterates through these folders to pull the files for each installation and then merges them together to conduct the analysis. The population estimates from LandScan are used to calculate current (2013) population density estimates for each buffer, while the urban development figures are used to determine the percentage growth of development. Further information on these methodologies can be found in Wilhoit et al. (2016). *

\footnotetext{
* A user may notice that the toolbox contains a number of other tools. These are submodels used in the MVA calculation process.
} 
A note on the LandScan files: the output of the analysis from the preprocessing model is produced in the form of info tables. When viewed in Windows Explorer, the output has the appearance of a folder called "info" (Figure 18). However, when the folder structure is viewed in ArcCatalog, it will show tables for each installation (Figure 19).

Figure 18. Windows view of LandScan analysis output.

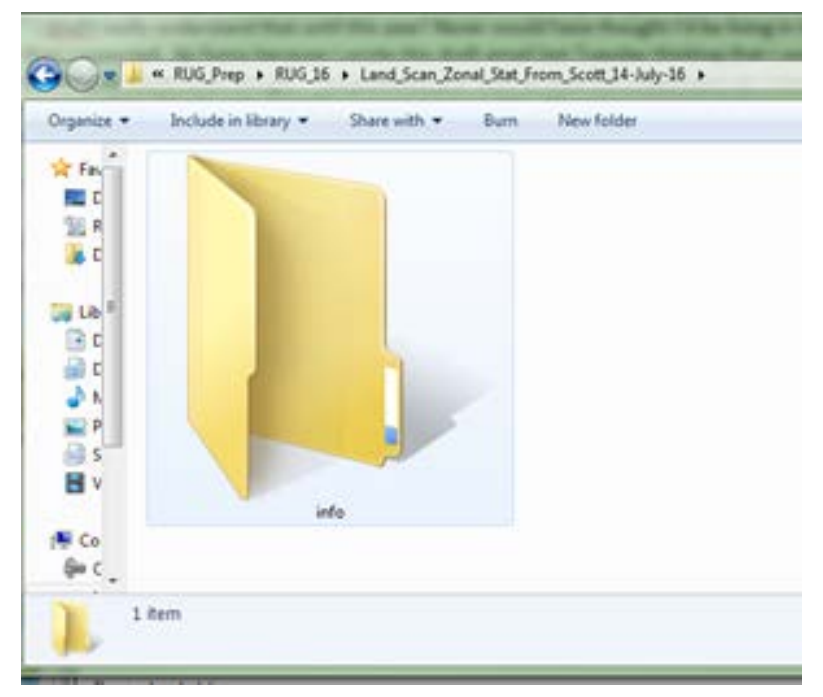

Figure 19. ArcCatalog view of LandScan analysis output.

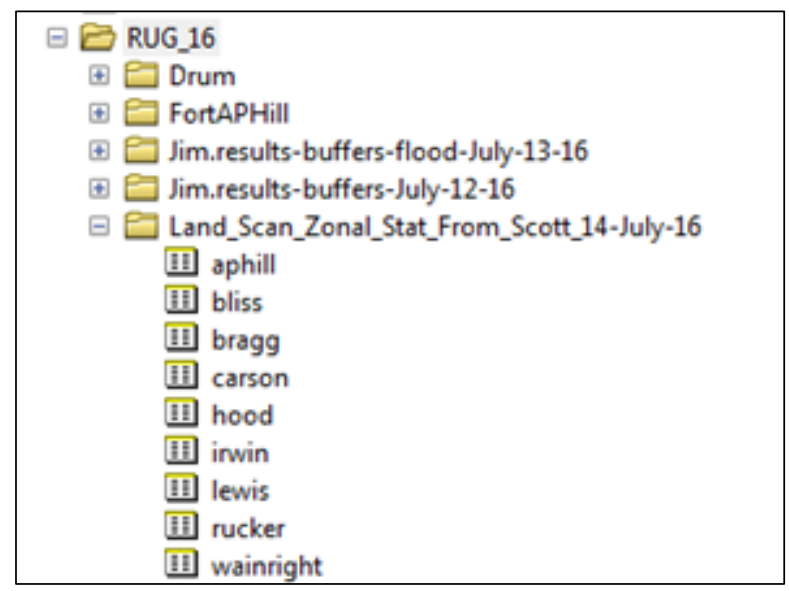

\subsubsection{Growth rate}

Using output from the Regional Urban Growth model, the projected new land development is calculated for each buffer in the initial year (year 1) and the final year (year 2) using the MVA calculation tool (Figure 20). Initial calculations were set to a 30-year period. Based on SME feedback and the possibility that the tool could be used to assess Net Present Value 
(NPV) calculated within a 20-year window, a variable in the model was included to allow for alternative year selection. These years are not the calendar year, but the years since the simulation started.

Figure 20. Screen shot of the MVA calculation tool showing fields for selecting years for analysis.

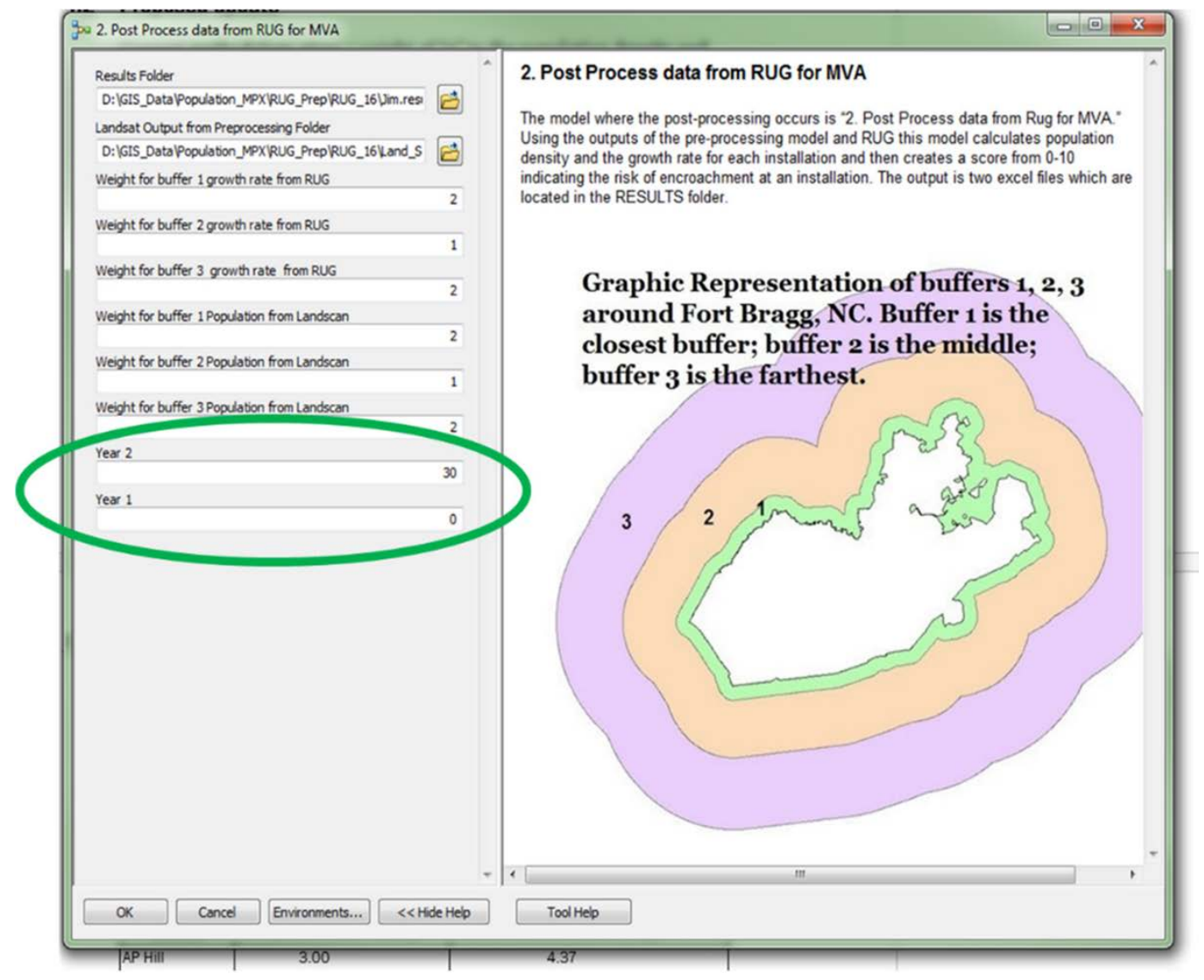

To calculate the growth within a region the following formula was used:

Year 2 Developed Area - Year 1 Developed Area

total amount of land which could be developed or is developed

This calculation differs from both the CAA methodology and the previous reports (Wilhoit et al. 2016). Rather than calculating a growth rate, the research team calculated the percent of new land developed from all the land available for development for each buffer region.

\subsubsection{Current population density}

The research team propose changing the source of population estimates from the U.S. Census block data to the LandScan population estimates 
from Oak Ridge National Laboratory (ORNL). This data set, which is provided free of charge to the federal government, reduces processing time and, because it provides population estimates at 30-meter resolution, allows population estimations to be developed at scales below 10 miles. Using the zonal statistics tool in the preprocessing data-preparation model, the estimated number of individuals in each buffer was calculated. Zonal statistics provide a summary of the data that intersect or are contained within another layer (ESRI 2014). Cells that are on the edge of two buffer zones may be included in multiple buffers. If a cell is within both the 1 mile and 5 mile buffer that cell's population is reflected in both estimates. To reduce this double counting, the population for each buffer is calculated individually (i.e., using 1 mile as a base and adding subsequent buffers onto that).

The post-processing model sums the population and area for each individual buffer zone together (e.g. buffer $2=$ buffer $1+$ buffer 2 ) and then divides by the area.

$$
\frac{\text { Population in buffer }}{\text { Miles }^{2}}
$$

\subsubsection{Running the post-processing model}

Navigate to the "2. Post Process data from Rug for MVA model" (see Figure 21). For specifics, the parameters used are outlined in Table 3 (next page). This tool reformats the outputs from RUG and Population Density into normalized scores. The required inputs are the folders containing the results, the weights, and years for analysis. The output of the model consists of two Excel spreadsheets that are placed into the results folder. The first spreadsheet is "Rug_Output_All," that contains all of the variables used in computing the MVA. A data dictionary explaining the headings is available in Appendix E. The second spreadsheet is "Rug_Output_Clean," which contains the MVA. 
Figure 21. Screen shot of the model dialog to produce an MVA.

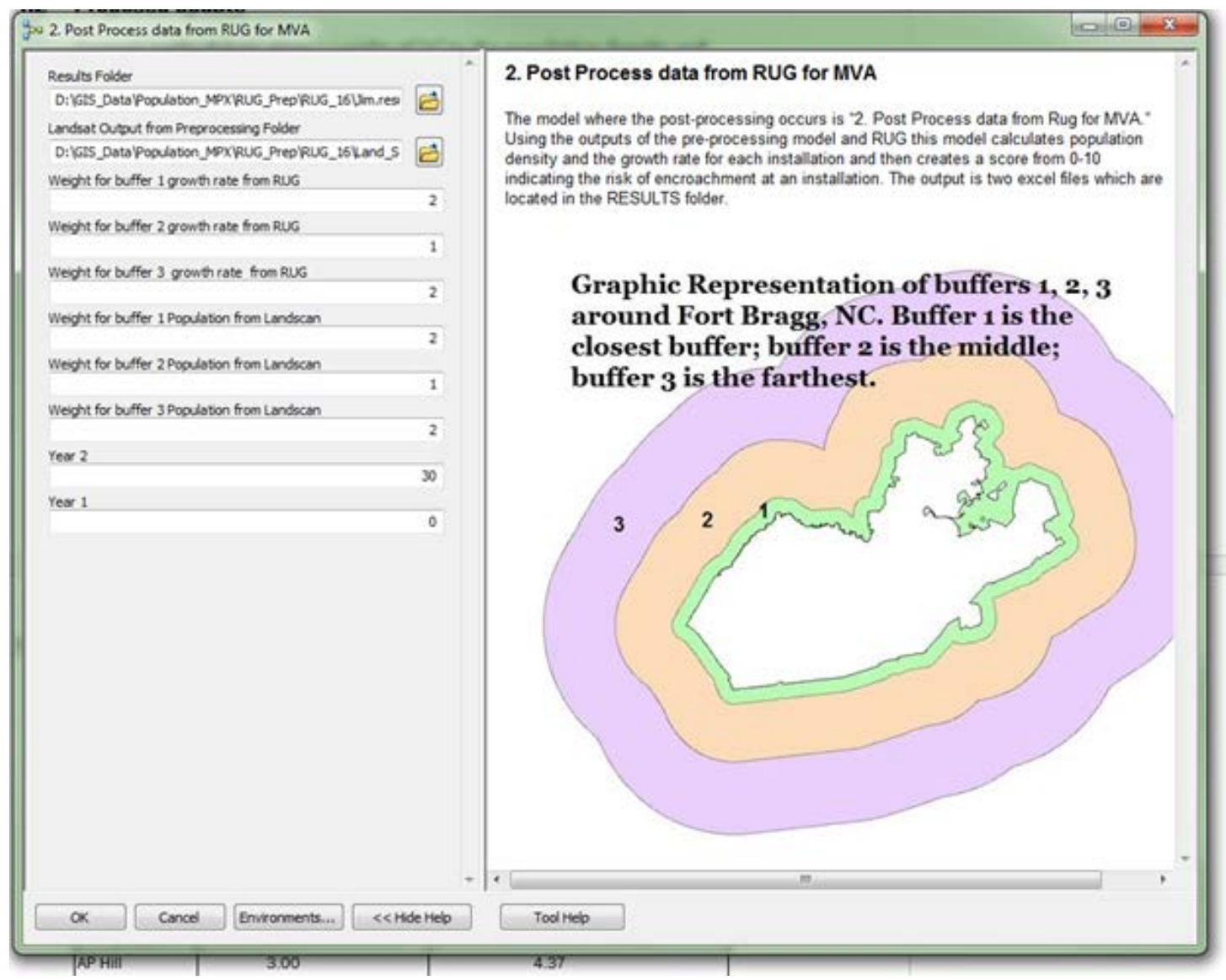

Table 3. Summary of the parameters for the model to compute an MVA.

\begin{tabular}{|l|l|l|}
\hline Parameter & Explanation & Data Type \\
\hline Results Folder & $\begin{array}{l}\text { The RESULTS folder is the output folder called "RESTULTS" from RUG which } \\
\text { contains the output files from the RUG runs. Within this folder there will be sub- } \\
\text { folders for each base. }\end{array}$ & Folder \\
\hline $\begin{array}{l}\text { LandScan Output from } \\
\text { Preprocessing Folder }\end{array}$ & $\begin{array}{l}\text { This is the output folder selected for the population during the preprocessing } \\
\text { stage. This contains the population from LandScan summarized for each buffer } \\
\text { from training areas. }\end{array}$ & Workspace \\
\hline $\begin{array}{l}\text { Weight for buffer 1 } \\
\text { growth rate from RUG }\end{array}$ & $\begin{array}{l}\text { Weight for the closest buffer (most likely 1 mile) from the ranges for growth rate } \\
\text { coming from RUG. Recommended weight is 2. The sum of all weights must sum } \\
\text { to 10. }\end{array}$ & Double \\
\hline $\begin{array}{l}\text { Weight for buffer 2 } \\
\text { growth rate from RUG }\end{array}$ & $\begin{array}{l}\text { Weight for the middle buffer (most likely } 5 \text { mile) from the ranges for growth rate } \\
\text { coming from RUG. Recommended weight is 1. The sum of all weights must sum } \\
\text { to 10. }\end{array}$ & Double \\
\hline $\begin{array}{l}\text { Weight for buffer 3 } \\
\text { growth rate from RUG }\end{array}$ & $\begin{array}{l}\text { Weight for the farthest buffer (most likely } 10 \text { mile) from the ranges for growth } \\
\text { rate coming from RUG. Recommended weight is 2. The sum of all weights must } \\
\text { sum to 10. }\end{array}$ & Double \\
\hline
\end{tabular}




\begin{tabular}{|c|c|c|}
\hline Parameter & Explanation & Data Type \\
\hline $\begin{array}{l}\text { Weight for buffer } 1 \\
\text { Population from } \\
\text { LandScan }\end{array}$ & $\begin{array}{l}\text { Weight for the closest buffer (most likely } 1 \text { mile) from the ranges for population } \\
\text { density from LandScan. Recommended weight is } 2 \text {. The sum of all weights } \\
\text { must sum to } 10 \text {. }\end{array}$ & Double \\
\hline $\begin{array}{l}\text { Weight for buffer } 2 \\
\text { Population from } \\
\text { LandScan }\end{array}$ & $\begin{array}{l}\text { Weight for the middle buffer (most likely } 5 \text { mile) from the ranges for population } \\
\text { density from LandScan. Recommended weight is } 1 \text {. The sum of all weights } \\
\text { must sum to } 10 \text {. }\end{array}$ & Double \\
\hline $\begin{array}{l}\text { Weight for buffer } 3 \\
\text { Population from } \\
\text { LandScan }\end{array}$ & $\begin{array}{l}\text { Weight for the farthest buffer (most likely } 10 \text { mile) from the ranges for } \\
\text { population density from LandScan. Recommended weight is } 2 \text {. The sum of all } \\
\text { weights must sum to } 10 \text {. }\end{array}$ & Double \\
\hline Year 2 & $\begin{array}{l}\text { The final year of the RUG results which you wish to use for the growth rate } \\
\text { assessment. }\end{array}$ & Double \\
\hline Year 1 & $\begin{array}{l}\text { The initial year of the RUG results which you wish to use for the growth rate } \\
\text { assessment. }\end{array}$ & Double \\
\hline
\end{tabular}

\subsection{Results for sample installations}

The final step in the analysis was to test the calculations by running the analysis on many installations. As a starting point for this test, the researchers used a list of installations provided by the Center for Army Analysis as their priority assessment installations. The specific interest in this assessment was the impact of growth to training areas, so only the installations with training areas were included. This methodology could be used for all installations, replacing the installation boundary for the training area boundary for buffering where no training areas exist. Because of the work done to automate the process, the total staff time required in creating the final output score was minimal. The total processing time was about 36 hours with less than 2 hours of staff involvement. The results are shown in Table 4.

Table 4. Summary of Population Impact MVA results.

\begin{tabular}{|l|r|}
\hline Installation & MVA score \\
\hline Jackson & 8.13 \\
\hline Richardson & 8.10 \\
\hline Hood & 6.46 \\
\hline Lewis & 5.87 \\
\hline Benning & 4.46 \\
\hline Dix & 4.26 \\
\hline Bliss & 4.13 \\
\hline Stewart & 3.86 \\
\hline Sill & 3.02 \\
\hline Bragg & 2.92 \\
\hline
\end{tabular}




\begin{tabular}{|l|r|}
\hline Installation & MVA score \\
\hline Riley & 2.63 \\
\hline Carson & 2.42 \\
\hline Knox & 2.29 \\
\hline Huachuca & 2.23 \\
\hline Campbell & 1.54 \\
\hline Rucker & 1.32 \\
\hline A.P. Hill & 1.32 \\
\hline Leonard Wood & 0.99 \\
\hline Drum & 0.91 \\
\hline Polk & 0.39 \\
\hline Wainwright & 0.28 \\
\hline Irwin & 0.27 \\
\hline
\end{tabular}

Changes made to the methodology to calculate MVA scores resulted in MVA scores which are appropriately scaled to demonstrate the risk posed by encroachment. Removing development growth as a part of the equation and replacing it with a metric for the percent of land that is developed produces better focus on the development impacts. The previously used growth rate calculation was susceptible to being skewed by a small amount of growth in an area with minimal growth. By then normalizing results one installation had a very high growth rate, while the others appeared to have none. As seen in Figure 22, the results of this analysis follow a linear path $\left(\mathrm{R}^{2}=0.9121\right)$ demonstrating that the results are well distributed and do not appear to have been adversely skewed by one installation.

Figure 22. Results from this methodology plotted to demonstrate the linear path.

\section{Graph of the Final Scores for the MVA Assessment demonstrating data follows a linear path}

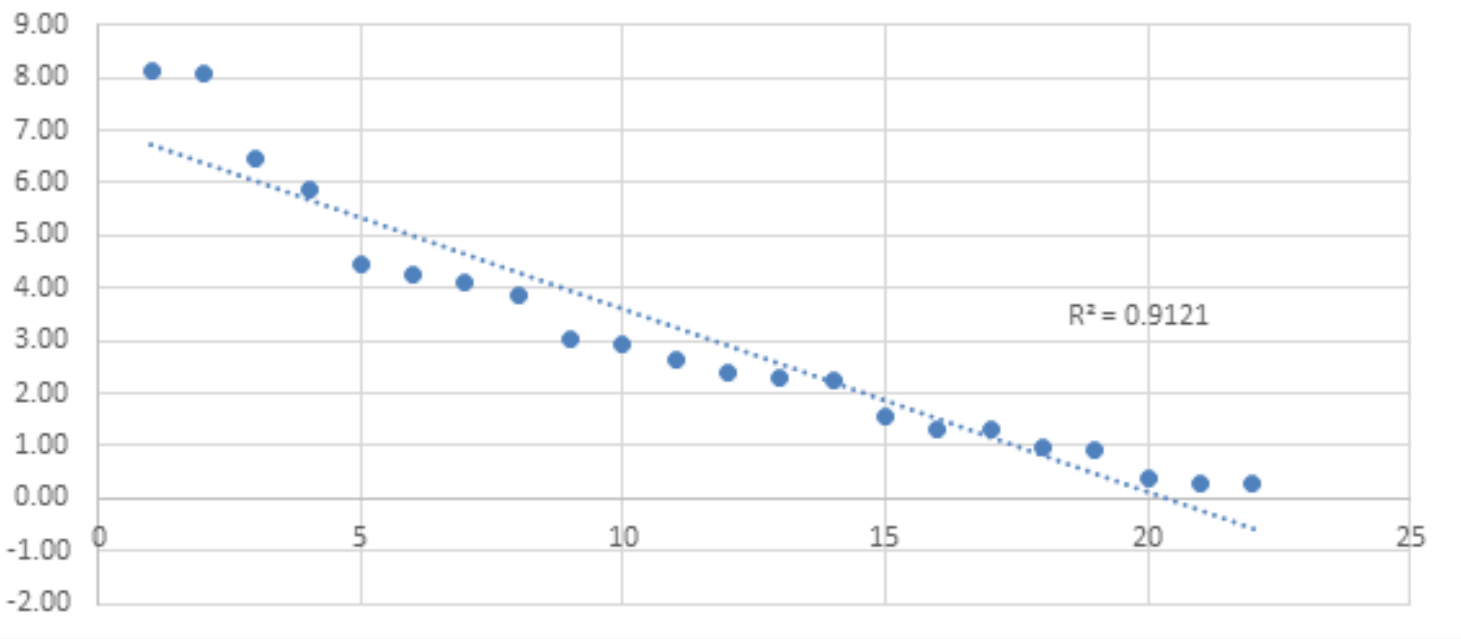


Furthermore, the results of the assessment can be verified through observation. The two installations located adjacent to moderately sized urban areas had the highest risk of population impact. Fort J ackson is adjacent to Columbia, SC, with a population of 133,358 in 2013. The Columbia region has experienced moderate growth over the past decade both from the installation as well as a growing local economy. The growth in the region and the current population pose a threat to training activities. Across the country outside of Anchorage, AK, is Fort Richardson. The city of Anchorage has a population of over 300,000, leading Fort Richardson to have the highest population density of any of the case study sites. Fort Hood, TX, has the highest expected growth within the 5 and 10 mile buffers over the next 30 years. This growth is offset by the current conditions of a lower population density than Forts J ackson and Richardson. 


\section{Conclusions and Recommendations}

\subsection{Conclusions}

The results of this analysis demonstrate that the impacts of encroachment from population will vary among installations, and it is therefore necessary to consider these impacts in making stationing decisions. The analysis has demonstrated that changing data sources to include rasterized population estimates and the results of a regional urban growth model provides an improved assessment of population impact. As Table 5 demonstrates, the changes to the MVA calculation do impact the score. All of these analysis were run exclusively on this subset of installations. Under the current methodology J oint Base Lewis-McChord (J BLM) has the highest score at 9.62, with Fort Carson having the next-highest score at 4.75. These figures represent a significant skewing in the results with the over-favoring of population density.

Table 5 Comparison of the three iterations of MVA score calculation per installation.

\begin{tabular}{|l|l|l|l|}
\hline Installation & $\begin{array}{l}\text { Current Population } \\
\text { Impact Score } \\
10 \text { mile population density (9), 10 } \\
\text { mile growth rate (1) }\end{array}$ & $\begin{array}{l}\text { FY15 Update to Population } \\
\text { Impact Method (Wilhoit 2016) } \\
10 \text { mile Population Density (2), 5 } \\
\text { mile Population Density (1), 1 mile } \\
\text { Population Density (2), 10 miles } \\
\text { Growth Rate (2), 5 miles Growth } \\
\text { Rate (1), 1 mile Growth Rate (2) }\end{array}$ & $\begin{array}{l}\text { FY16 Update to Population } \\
\text { Impact Method } \\
\text { 10 mile Population Density (2), 5 } \\
\text { mile Population Density (1), 1 mile } \\
\text { Population Density (2), 10 miles } \\
\text { Growth Rate (2), 5 miles Growth } \\
\text { Rate (1), 1 mile Growth Rate (2) }\end{array}$ \\
\hline AP Hill & 3 & 4.37 & 1.32 \\
\hline Bliss & 3.23 & 1.95 & 4.13 \\
\hline Bragg & 4.63 & 5.15 & 2.92 \\
\hline Carson & 4.75 & 3.20 & 2.42 \\
\hline Hood & 3.56 & 5.70 & 6.46 \\
\hline Irwin & 0 & 1.90 & 0.27 \\
\hline JBLM & 9.62 & 7.58 & 5.87 \\
\hline Rucker & 1.47 & 2.46 & 1.77 \\
\hline Wainwright & 0.92 & & 1.32 \\
\hline
\end{tabular}

Plotting the curves, as shown in Figure 23, demonstrates the fit of the results. Of the three approaches analyzed, the methodology currently used by CAA had the lowest R2, at 0.84 while the approach described in the present report had the highest, at 0.94. An even distribution of results is not necessary for the MVA to be an accurate tool, as some installations may have a far higher encroachment risk than others. However, the large 
differences in scores between installations may demonstrate an error with the methodology in that it is over-favoring one category.

Figure 23. Comparison of result curve for each of the population impact methodologies.

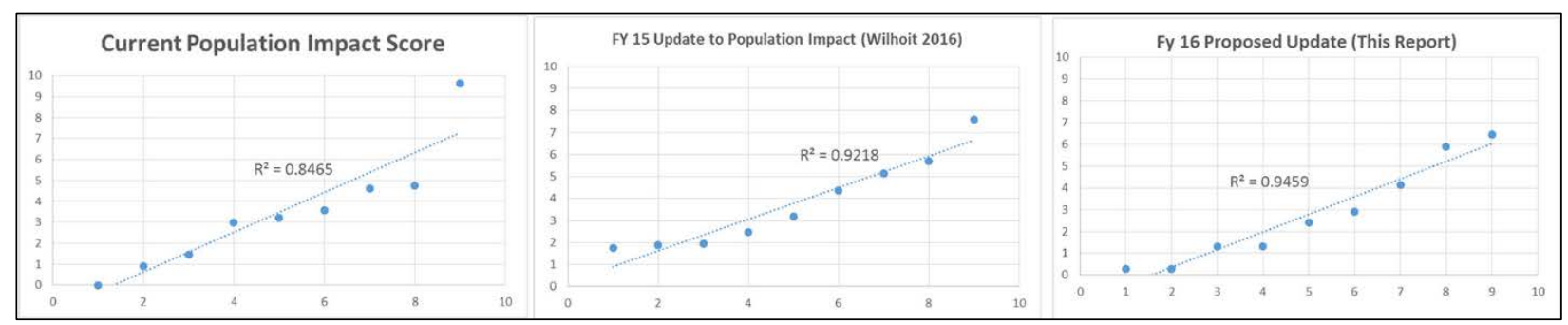

\subsection{Recommendation}

The results of this work provide a foundation for studies to validate and confirm the benefits of an urban growth approach to the current linear model. Using historic data from NLCD, the methodology could be used to forecast current development patterns around installations. The results of such a study could be compared with the results of the linear population growth estimates for a similar time period. 


\section{References}

Army Regulation 10-5. 1992. Organization and Functions. Washington, DC: Headquarters, Department of the Army.

Bierwagen, Britta, and Phil Morefield. "Integrated Climate and Land Use Scenarios (ICLUS)." http://134.67.99.51/ICLUSonline/, accessed 25 September 2014.

Caldwell, Peter, Ge Sun, Steve McNulty, J ennifer Moore Myers, Erika Cohen, Robert Herring, and Erik Martinez. 2013. “WaSSI Ecosystem Services Model: User Guide." http://admin.forestthreats.org/research/tools/WaSSI/WaSSIUserGuide_english_v1.1.pdf.

Center for Army Analysis. 2015. Population Impact. Fort Belvoir, VA: Center for Army Analysis.

Climate Change Sensitivity Database [CCSD]. 2012. Climate Change Sensitivity Database. http://climatechangesensitivity.org/, accessed 15 Sep 2015.

CNA Military Advisory Board. 2014. National Security and the Accelerating Risks of Climate Change. Alexandria, VA: CNA.

Cohn, J .P. 1996. "New Defenders of Wildlife: Practicing Conservation and Protecting Hhabitat are not Usually Considered Parts of the Military's J ob Description." Bioscience 46(1):11-14.

Daggett, S. 2010. Quadrennial defense review 2010: over-view and implications for national security planning. Congressional Research Service. http://dtic.mil/dtic/tr/fulltext/u2/a522091.pdf, accessed 24 September 2015.

Deal, Brian, and Varkki Pallathucheril. 2009. "A Use-Driven Approach to Large-Scale Urban Modelling and Planning Support." In Planning Support Systems Best Practice and New Methods, edited by Dr. Stan Geertman and Professor J ohn Stillwell, 29- 51. The GeoJ ournal Library 95. Springer Netherlands. http://link.springer.com.proxy2.library.illinois.edu/chapter/10.1007/978-1-4020-8952-7_2.

ESRI. 2014. "Zonal Statistics (Spatial Analyst).” ArcGIS Help 10.2. http://resources.arcgis.com/EN/HELP/MAIN/10.2/index.html\#//009z000000w7000000.

Füssel, H.-M., and Klein, R. J.T. 2006. Vulnerability and Adaptation Assessments to Climate Change: An Evolution of Conceptual Thinking. Climatic Change 75: 301329.

Füssel, H.-M. 2007. “Adaptation Planning for Climate Change: Concepts, Assessment Approaches, and Key Lessons." Sustainability Science 2:265-275.

Gardali, T., N.E. Seavy, R.T. DiGaudio, and L.A. Comrack. 2012. A Climate Change Vulnerability Assessment of California's At Risk Birds. PloS One 7:1-13.

Glick, P., B.A. Stein, and N.A. Edelson, editors. 2011. Scanning the Conservation Horizon: A Guide to Climate Change Vulnerability Assessment. Washington, D.C: National Wildlife Federation. 
Homeland Infrastructure Foundation-Level Data. 2012. "Homeland Security Infrastructure Program (HSIP)." https://www.hifldwg.org/hsip-guest.

LandScan-Documentation. http://web.ornl.gov/sci/landscan/landscan_documentation.shtml, accessed 23 September 2015.

Leslie, M., G.K. Meffe, J .L. Hardesty, and D.L. Adams. 1996. Conserving Bio-diversity on Military Lands: A Handbook for Natural Resource Managers. Arlington, VA: The Nature Conservancy.

Mawdsley, J., and R. Lamb. 2013. Climate-Change Vulnerability Assessment for Priority Wildlife Species (of the Navajo Nation). Washington, DC: The H. J ohn Heinz III Center for Science, Economics and the Environment.

McCarthy, J .J ., O.F. Canziani, N.A. Leary, D.J . Dokken, and K.S. White (eds). 2001. Climate Change 2001: Impacts, Adaptation and Vulnerability. Cambridge, MA: Cambridge University Press.

Nature Conservancy, The. 2009. Climate Wizard website. Arlington, VA: The Nature Conservancy. http://www.climatewizard.org/index.html.

NatureServe. 2011. NatureServe Explorer: An online encyclopedia of life [Web application]. Version 7.1. http://www. na-tureserve.org/explorer. Arlington, VA: NatureServe.

Office of the Deputy Under Secretary of Defense. 2014. Climate Change Adaptation Roadmap. Washington, DC: Department of Defense.

Stein, B.A., C. Scott, and N. Benton. 2008. Federal lands and Endangered Species: The Role of Military and Other Federal Lands in Sustaining Biodiversity. Bioscience 58 (4):339-347.

Strategic Environmental Research and Development Program. 2013. Assessing Impacts of Climate Change on Coastal Military Installations: Policy Implications. Washington, DC: Department of Defense.

Under Secretary of Defense (Personnel and Readiness). 2014. "Report to Congress on Sustainable Ranges.” 2-F995972. Washington, DC: Department of Defense.

U.S. Bureau of Economic Analysis (BEA). 2014. “Personal Income, Population, Per Capita Personal Income (CA1)."

http://www.bea.gov/iTable/iTable.cfm?reqid=70\&step $=1 \&$ isuri $=1 \&$ acrdn $=5 \#$ reqid $=70 \& s t e p=1$

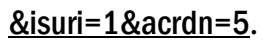

Westervelt, J ames, Todd BenDor, and J oseph Sexton. 2011. “A Technique for Rapidly Forecasting Regional Urban Growth.” Environment and Planning B: Planning and Design 38 (1): 61- 81. doi:10.1068/b36029.

Wilhoit, J. M., S. Tweddale, M. G. Hohmann, D. Delaney, M. E. Swearingen, and J . Westervelt. J anuary 2016. Effects of Climate Change, Urban Development, and Threatened and Endangered Species Management on Army Training Capabilities: Training Ranges. ERDC/ CERL TR-16-29. Champaign, IL: ERDCCERL. 
Young, B., E. Byers, K. Gravuer, K. Hall, G. Hammerson, and A. Redder. 2011. Guidelines for using the NatureServe climate change vulnerability index Release 2.1. Arlington, VA: NatureServe. 


\section{Appendix A: Current Population Impact MVA Definition (CAA 2015)}

\section{Population Impact \\ As of: 09 FEB 2015}

1. Definition: The impact of population density and growth rate in a ten mile buffer outside the installation.

2. Purpose: The population impact attribute attempts to address potentially negative impacts on an installation and the nearby communities created by changes in population of the surrounding area over time. It also serves as an indicator of potential encroachment issues relating to noise complaints, reduction of natural buffer land surrounding installation boundaries, light pollution effects on nighttime training operations and other potential impacts to operations on installations. Thus, the higher the population impact score, the lower the potential value to the military.

3. POC: U.S. Army Environmental Command (AEC): Mr. Jeff Salmon (jeff.a.salmon.civ@mail.mil)

4. Data Source: U.S. Census, Army Mapper, HQIIS

\section{Methodology:}

a. Obtain the most recent decennial census geospatial data (with population statistics at the census block level) and the decennial data from 10 years prior to the most recent data set. Decennial census data are used because it is more accurate than population estimates developed in the interim years and is collected down to the census block level.

b. Use the buffer tool in ArcGIS software to create a ten mile buffer area around the installation. See Figure 1. Per guidance for this version of the Military Value Analysis, data for non-contiguous training areas are not included for this attribute in this time*.

i. A standardized set of geospatial data for installation boundaries is required. Currently, AEC uses installation boundaries from Army Mapper, the Army’s geospatial data set of record for installations.

\footnotetext{
* AEC ran an analysis that included sub-installations, administered by the main installation according to HQIIS data. This information is available upon request. An improved version of the MVA may consider non-contiguous training areas when evaluating population impacts.
} 
ii. The installation boundaries maintained in Army Mapper are the notional site boundaries, not the legal boundaries which are maintained by the U.S. Army Corps of Engineers.

iii. Ten miles was chosen as the buffer area by subject matter experts, based on factors such as noise, road infrastructure, and a comparison of the population densities around the installations.

c. Add decennial census block data to the project. See Figure 2.

d. Select census block polygons where the polygon centroid of the census blocks is within the polygon representing the ten mile buffer of the installation. See Figure 3.

i. The location of the centroid of the census block polygon is used to determine if the census block is included in the population total for the ten mile buffer. If the census block polygon centroid lies outside of the ten mile buffer, the entire polygon is excluded from the analysis.

ii. Create a new data layer with the census blocks selected from the overlay analysis.

e. Determine the total population for all of the census blocks that were selected from the overlay analysis. The best way to do this is by opening the attribute table for the census blocks data layer and summarizing the population data field for the total population.

f. Determine the square miles of the ten mile buffer zone surrounding the installation being analyzed. The best way to do this is by adding a new field to the attribute table for the buffer data layer and using the "calculate geometry function" to determine the total square mileage and automatically add that information to the new data field.

g. Divide the total population of the selected census blocks by the square mileage of the buffer area (step f) to calculate the current population density per square mile.

h. Normalize the current population density and scale the range of values to a score that ranges from 0 to 9 .

i. Calculate the percentage change in population between the most current census population (i.e., 2010) by the census population from 10 years prior (i.e., 2000) to determine the rate of population change.

j. Normalize the percentage changes in population and scale the range of values to a score that ranges from 0 to 1 .

\section{Equations:}

a. 2010 Population Density per Square Mile = population / 10-mile buffer area (in sq. mi.) 
b. Normalized Population Density $=\mathrm{b}+\left[\left(\mathrm{X}-\mathrm{X}_{\min }\right)(\mathrm{a}-\mathrm{b}) /\left(\mathrm{X}_{\max }-\right.\right.$ $\left.\mathrm{X}_{\mathrm{min}}\right)$ ], where $a$ represents the highest score for the data set, $b$ represents the lowest score for the data set, and $X$ is population density per square mile. For the population density, $a=9, b=0$.

c. Growth Rate/yr $=($ ( 2010 population -2000 population $) / 2000$ population) $) / 10$ (years)

d. Normalized Growth Rate $=b+\left[\left(X-X_{\min }\right)(a-b) /\left(X_{\max }-X_{\min }\right)\right]$, where $a$ represents the highest score for the data set, $b$ represents the lowest score for the data set, and $X$ is growth rate/yr. For the growth rate/yr, $a=1 ; b=0$.

e. Population Impact Score $=$ Normalized Population Density + Normalized Growth Rate [10 is the maximum score for any installation and 0 is the minimum score].

The normalized population density and normalized growth rate, being unitless, are added together for the Population Impact Score. This results in a weight factor of $90 \%$ on current population density and $10 \%$ on growth rate over last $10 \%$ years*.

Figure A1. Ten mile buffer with census tracts overlaid.

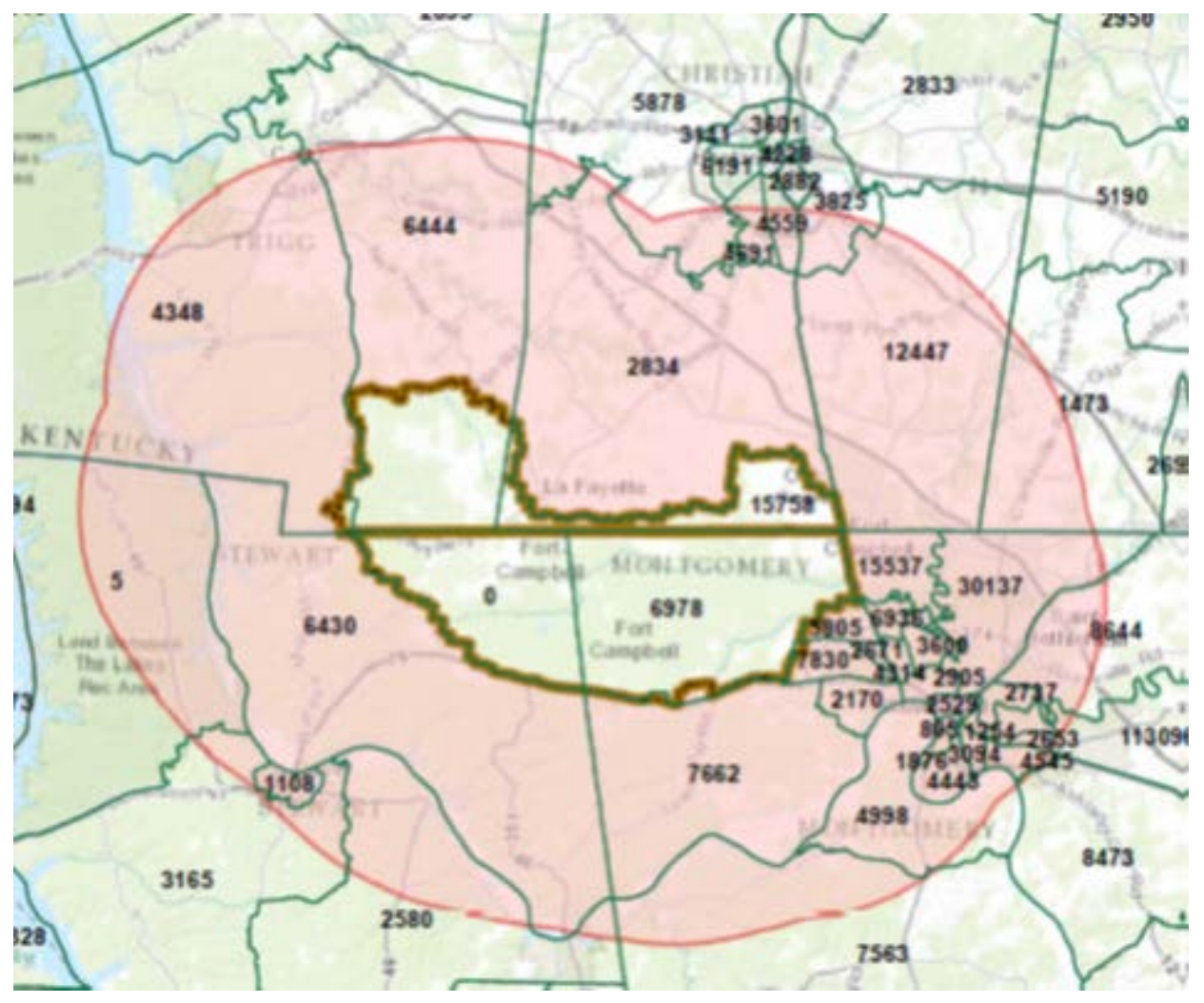

* The sensitivity of the model to the relative weights of density and growth was tested at ratios of 8:2, 7:3 and 5:5. It was determined that the results are not sensitive to these weights and the relative rankings changed little with different weighting schemes. 
A snapshot of a ten mile buffer (red) surrounding Ft. Campbell with census tract geography (green polygons) overlaid. Census tract geography is too large to obtain accurate population statistics for the area within the ten mile buffer area alone.

Figure A2. Ten mile buffer with census blocks overlaid.

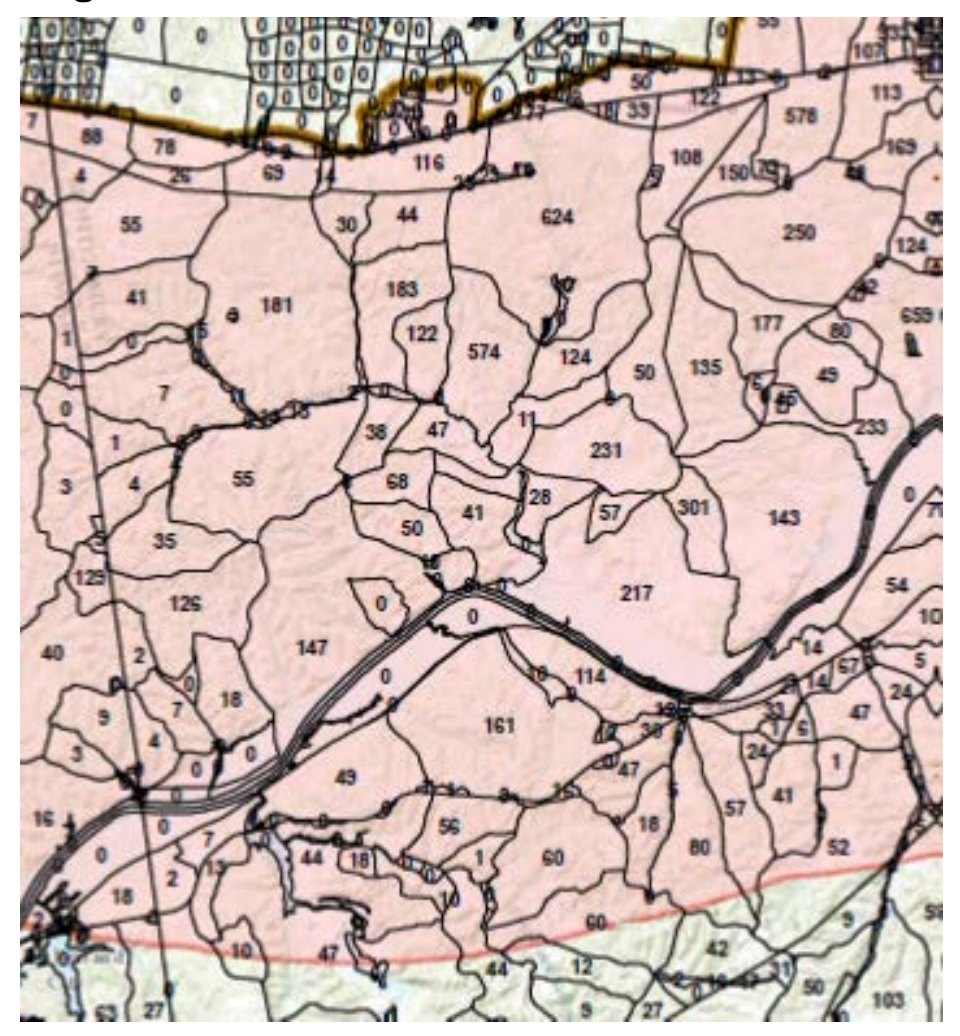

A snapshot of a ten mile buffer (red) surrounding Ft. Campbell with census block geography (black polygons) overlaid. Census block geography is nested within census tracts and block groups. It is the lowest level of census geography available. Geospatial analysis at this level of census geography provides for the most accurate population statistics. 
Figure A3. Ten mile buffer with census blocks and census block centroids overlaid.

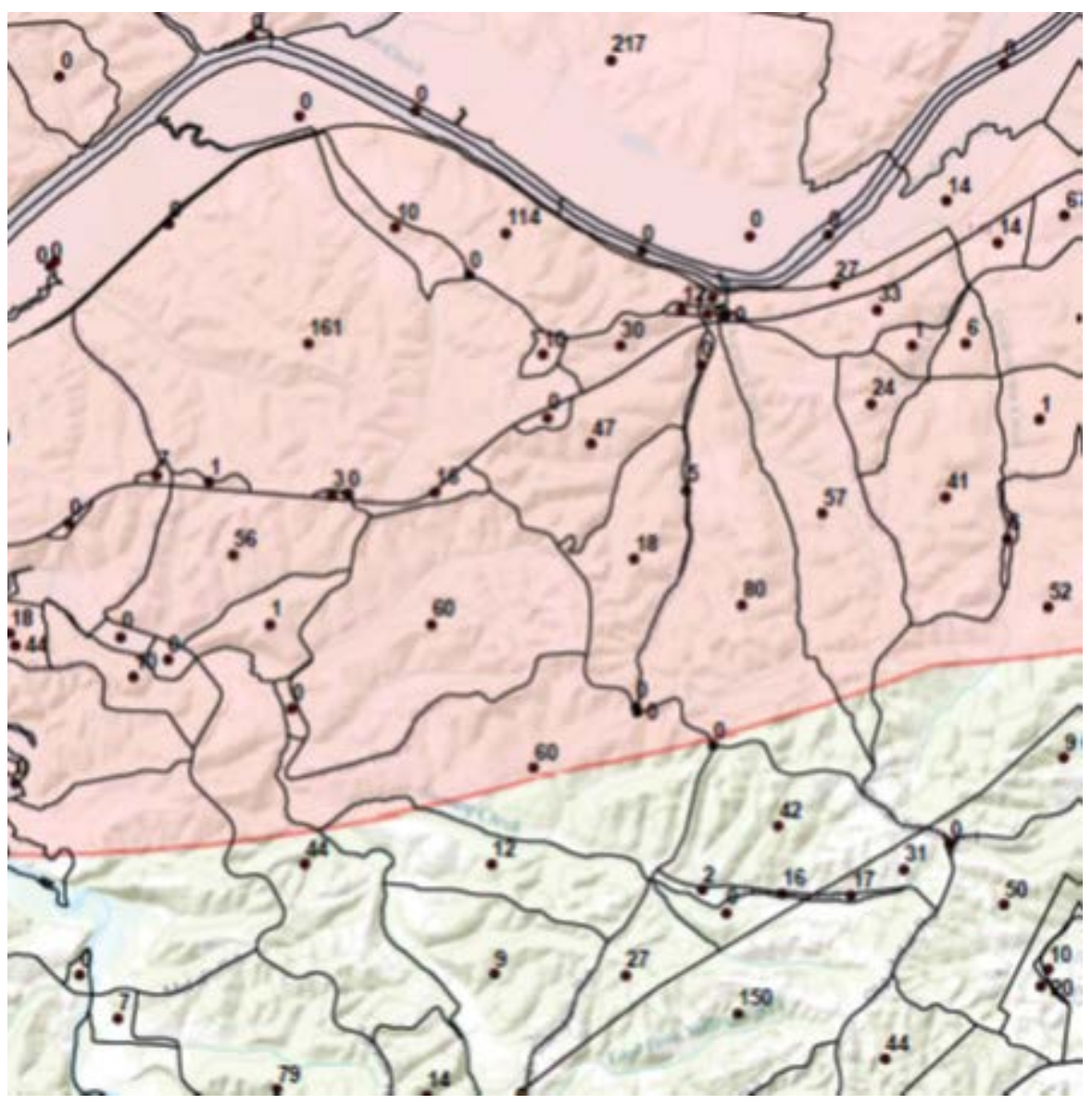

A snapshot of a ten mile buffer (red) surrounding Ft. Campbell with census block geography (black polygons) and census block centroids (points) overlaid. ArcGIS software is used to geospatially select only the census blocks with their centroids within the ten mile buffer. Census blocks with their centroids outside of the buffer area are entirely eliminated from the selection and not included in the population statistics. 


\section{Appendix B: Proposed Population Impact MVA Definition}

\section{Proposed Population Impact}

As of: 30 September 2016

1. Definition: The impact of population density and growth rate in a ten mile buffer outside the ranges on the installation.

2. Purpose: The population impact attribute attempts to address potentially negative impacts on an installation and the nearby communities created by changes in population of the surrounding area over time. It also serves as an indicator of potential encroachment issues relating to noise complaints, reduction of natural buffer land surrounding installation boundaries, light pollution effects on nighttime training operations and other potential impacts to operations on installations. Thus, the higher the population impact score, the lower the potential value to the military.

3. POC: U.S. Army Environmental Command (AEC): Mr. Jeff Salmon (jeff.a.salmon.civ@mail.mil)

4. Data Source: Landscan from Oak Ridge National Lab, sustainable ranges program, output of regional urban growth model, National Map

\section{Methodology:}

a. Obtain the most recent LandScan night population data for CONUS, Alaska, and Hawaii. level.

b. Use the preprocessing model prepare data developed by ERDCCERL. Accept the default settings for buffer distance of Use the multi-ring buffer tool in ArcGIS software to create a buffers of 1 , 5, and 10 miles around the training areas of an installation. This will process the data required for running the Regional Urban Growth model as well as prepare population data.

i. A standardized set of geospatial data for installation ranges is required. The Sustainable Ranges Program maintains a national data set of training areas. Furthermore, as this analysis seeks to assess the impact of population growth not just on the main installation but also on non-contiguous areas a list of training areas will have to be obtained. The Army Environmental Command does not have such a list, so this would need to be obtained through a data call.

ii. Buffers of 1, 5, and 10 miles were chosen as the buffer areas by subject matter experts, based on factors such as 
noise, road infrastructure, and a comparison of the population densities around the installations.

c. Run an urban growth model, such as the Regional Urban Growth (RUG) model to produce estimates of future population.

i. Input the results of the growth model to the ERDC-CERL post-processing tool. Accept the defaults for normalizing population density and development:

Normalize the current population density to have a minimum of 0 and a maximum of the value listed below:

ii. 10 mile Population Density: 2

iii. 5 mile Population Density: 1

iv. 1 mile Population Density: 2

v. 10 miles Growth Rate: 2

vi. 5 miles Growth Rate: 1

vii. 1 mile Growth Rate: 2

viii.

d. Sum Normalized Population Density and Normalized Growth Rate to receive a score with maximum of 10 . If an installation has an ACUB program, subtract one (1) from the total.

\section{Equations:}

a. 2010 Population Density per Square Mile = population / 10-mile buffer area (in sq. mi.)

b. Normalized Population Density $=\mathrm{b}+\left[\left(\mathrm{X}-\mathrm{X}_{\min }\right)(\mathrm{a}-\mathrm{b}) /\left(\mathrm{X}_{\max }-\right.\right.$ $\left.\mathrm{X}_{\mathrm{min}}\right)$ ], where $a$ represents the highest score for the data set, $b$ represents the lowest score for the data set, and $X$ is population density per square mile. For the population density, $a=$ value listed in 5.f , $b=0$.

c. Growth Rate/yr = (Year 2 Developed Area -Year 1 Developed Area)/ total amount of land which could be developed or is developed ( (2041 Developed Area - 2011 Developed Area) / 2011 Developed Area))/30 (years)

d. Normalized Growth Rate $=\mathrm{b}+\left[\left(\mathrm{X}-\mathrm{X}_{\min }\right)(\mathrm{a}-\mathrm{b}) /\left(\mathrm{X}_{\max }-\mathrm{X}_{\min }\right)\right]$, where $a$ represents the highest score for the data set, $b$ represents the lowest score for the data set, and $X$ is growth rate/yr. For the growth rate/yr, $a=$ value listed in 5.i; $b=0$. 


\section{Appendix C: Errors Identified in Application}

As with many software platforms there can be errors in the process. We have tested the models and believe that we have built a solid code base to prevent errors. Below are a few of the errors received during testing and the work arounds that were developed.

\section{Output raster extents are not the same size}

The ASCII raster files created by the preprocessing model that are used as input to RUG should have the same number of columns and rows across all rasters, indicating identical extents. Check the number of rows and columns by going to ArcCatalog, navigating to the ASCII raster file, right clicking on the file and selecting properties.

Another way to check the output is visually. Right click on the raster in the table of contents > Properties > Symbology. On that tab change the "Display NoData as" to a color of your choice. Then zoom in and see if the extents match.

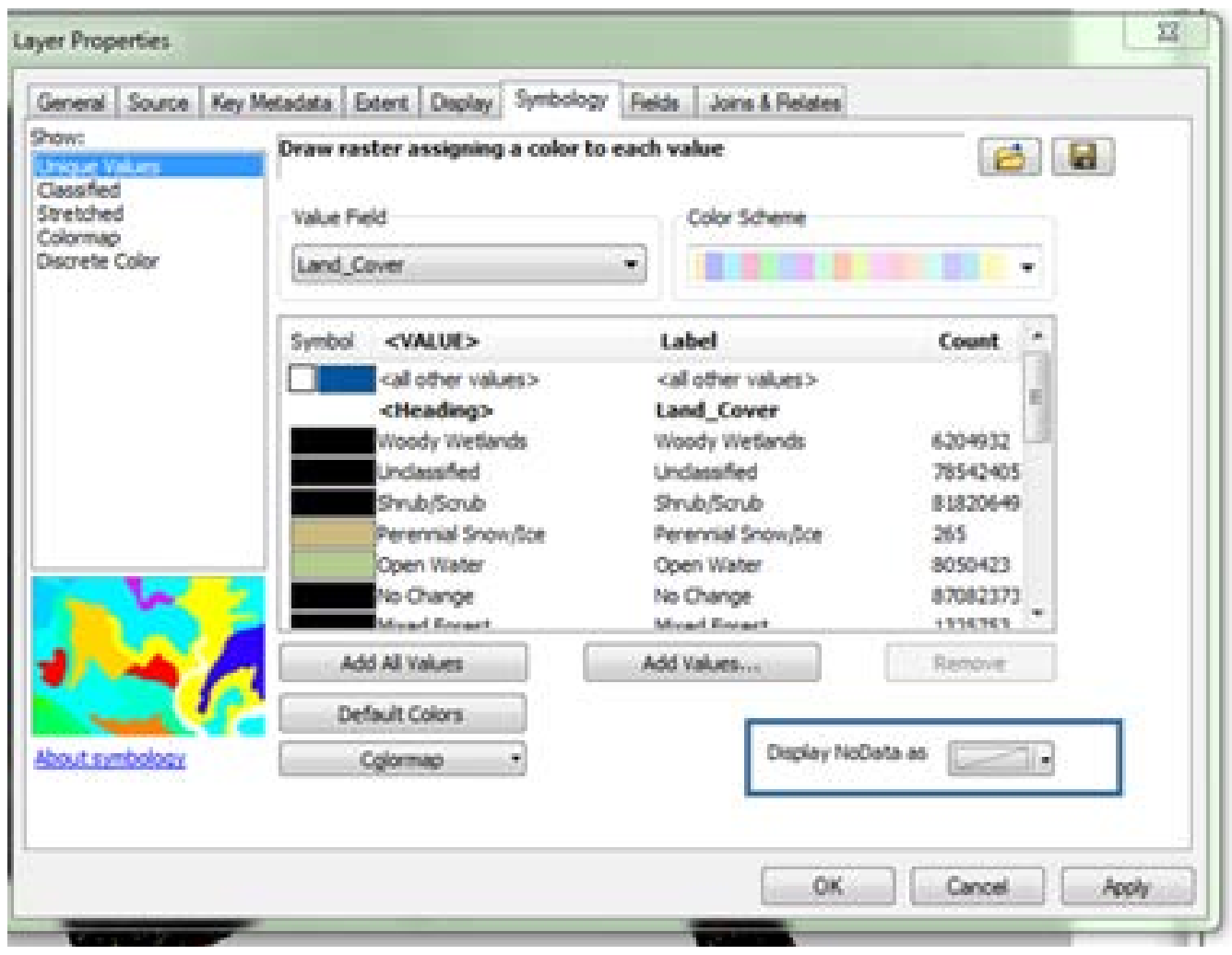


We found that the outputs were not the same extent and this was because input files had not been projected prior to the running of the model.

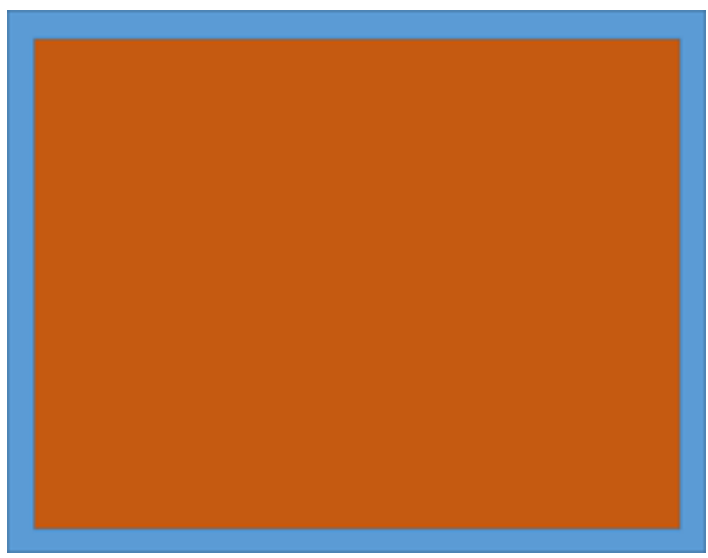

ERROR 9999 Tool fails with error "The table was not found ...Invalid Topology [Z coord limit exceeded]"

This error was received in testing the data-preparation model where the model would run partially and stop. Per ESRI support (http:// support.esri.com/ fr/ knowledgebase/ techarticles/ detail/41857) this can be an issue with older shapefiles. The problem was resolved by making a copy of the installation shapefile.

\section{ERROR 9999 Tool fails with error "Failed to execute (Add LandScan 5 Mile)"}

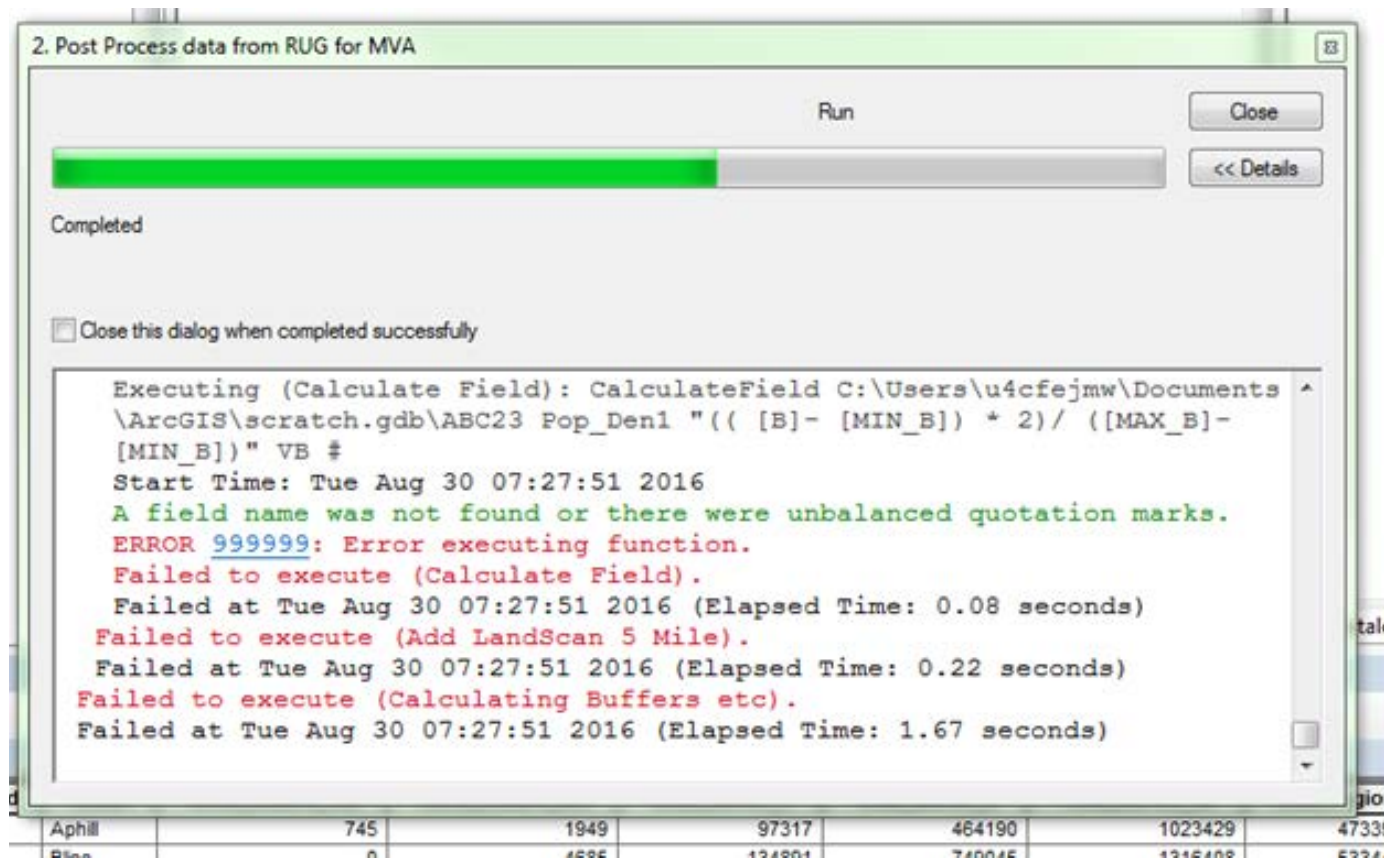


This error occurs in the post-processing stage to calculate the MVA output and is caused by an error in the reading of the LandScan data. This is caused when the model is run using the model builder view rather than running it as a tool. To resolve the issue simply re-run the entire tool.

ERROR 000732: Input Rows: Dataset \%Results Folder\%lpct_low_density_urban_in_buffers.csv

You may receive an error when you run the model for preparing the MVA that the dataset \%Results Folder\%lpct_low_density_urban_in_buffers.csv does not exist or is not supported. Due to an error in the esri Model Builder software, there must be a folder called "Workspace" containing an empty file called "pct_low_density_urban_in_buffers.csv" for the post processing tool to work. As a work around, we created a tool which creates this workspace folder and an empty csv. Run the "1. Create Workspace Folder" tool from the toolbox. The only parameter is Results Folder which is the location for the folder with the results from the RUG runs.

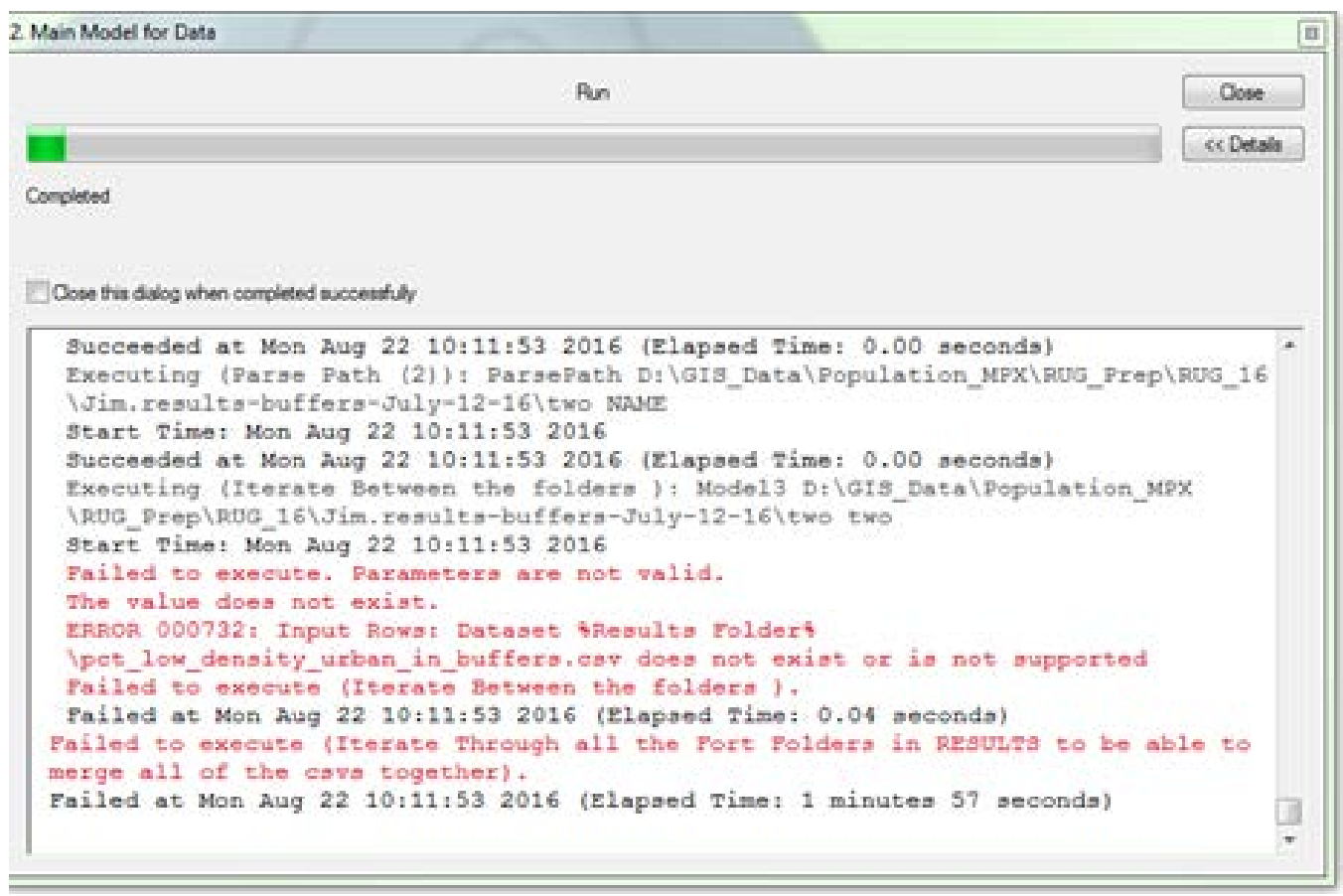

\section{ERROR 999999: "Failed to execute Calculate 100 year 2"}

ERROR 999999: Error executing function.

Failed to execute (Calculate Field).

Failed at Wed Sep 07 09:24:13 2016 (Elapsed Time: 0.26 seconds)

Failed to execute (Calculate 100 year 2). 
Failed at Wed Sep 07 09:24:13 2016 (Elapsed Time: 1.23 seconds)

This was an error received regularly during the testing of the model and validation. This error results from a table issue. After each time that this error was received, if the model was re-validated the model would run successfully. 


\section{Appendix D: ArcGIS Tips and Tricks}

Step \#1: Connect to folder

First connect to the folder containing your data in ArcMap. For more information on connecting to a folder visit: http:// desktop.arcgis.com/ en/arcmap/10.3/map/ working-with-arcmap/using-folderconnections.htm.

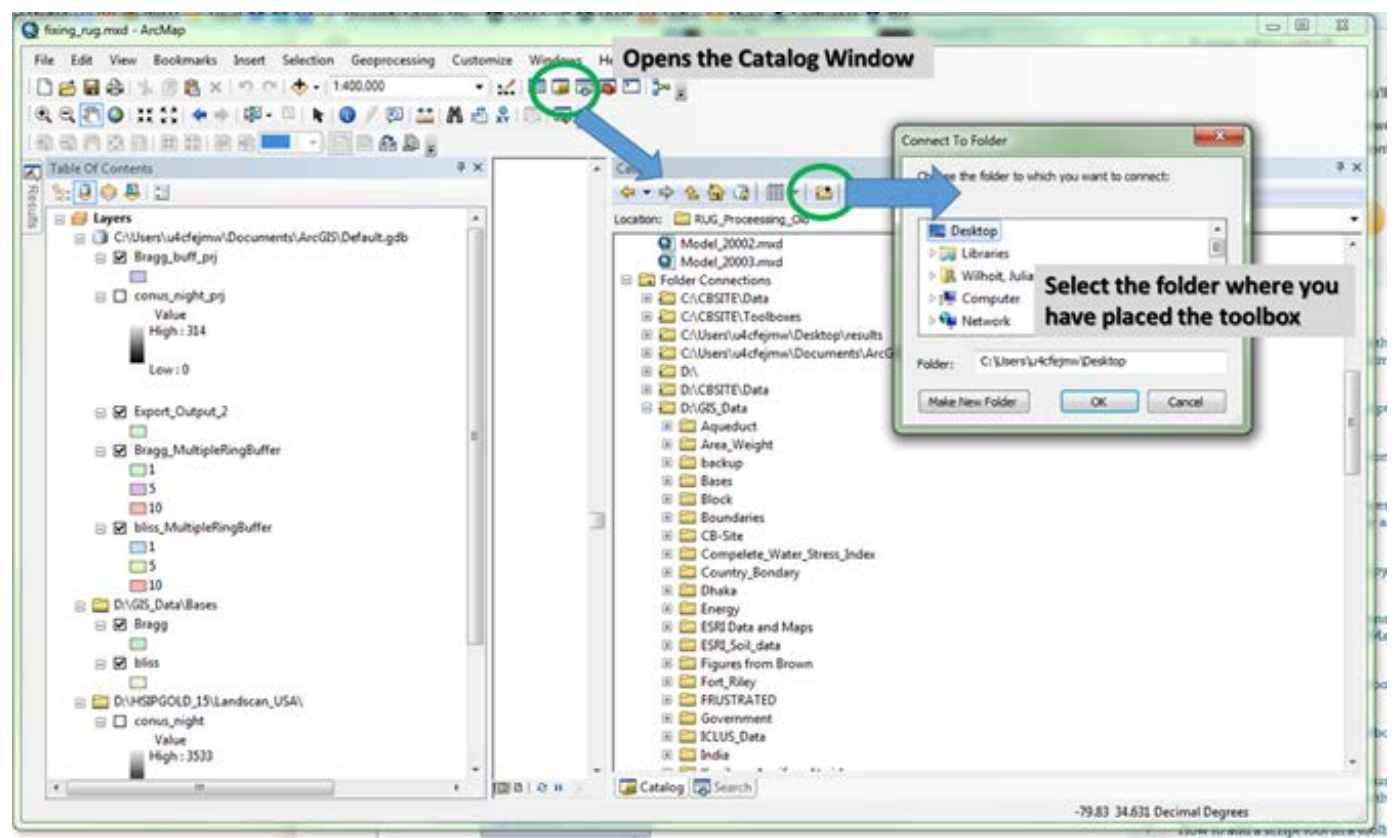

Step \# 2: Using the catalog window find the toolbox and double click on the tool you wish to run. Navigate to the appropriate folder which contains your data. Select "ok" to run. 


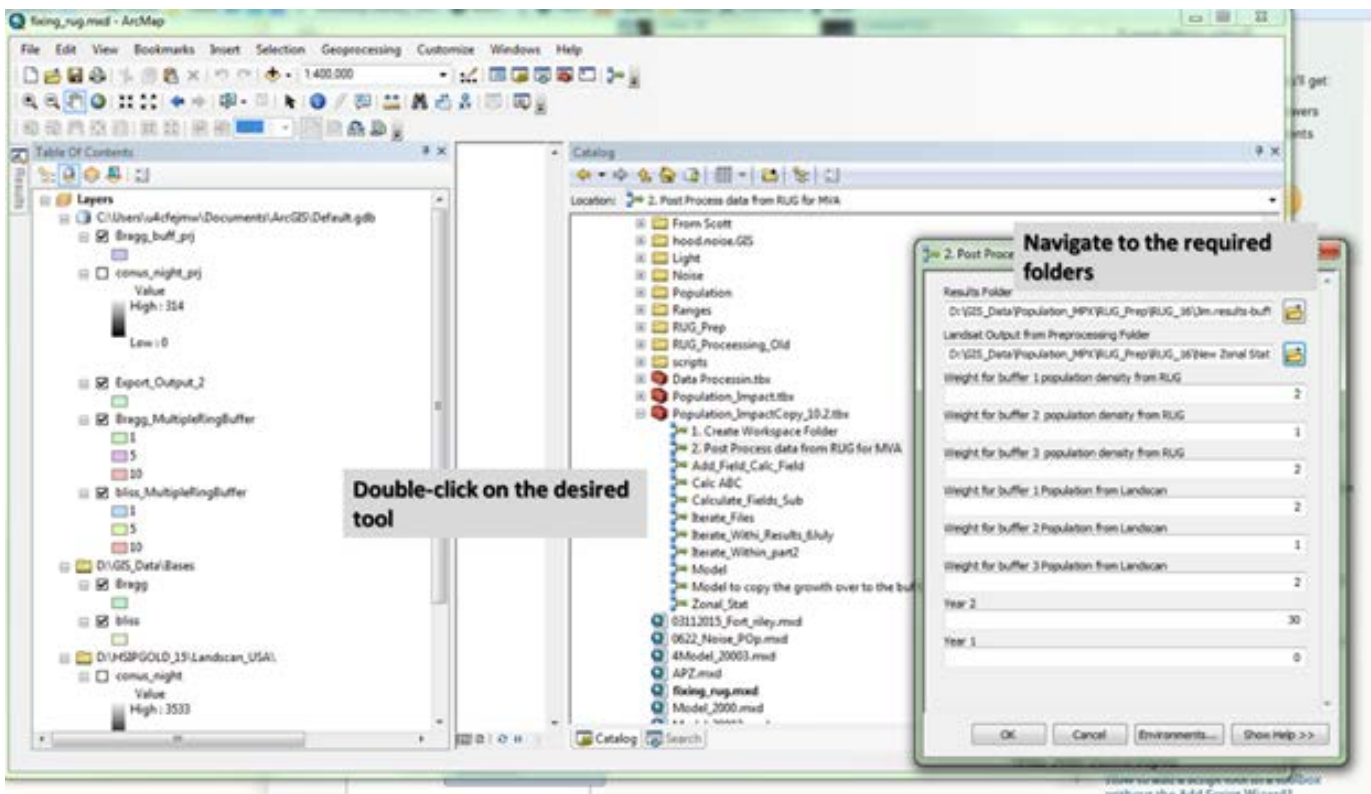




\section{Appendix E: Data Dictionary for Headings in RUG Output}

Table E1. Summary of the fields contained in the RUG output.

\begin{tabular}{|l|l|}
\hline RUG Field & Definition \\
\hline year & Year from start of simulation \\
\hline buffer-1 & Developed land within buffer 1 \\
\hline buffer-5 & Developed land within buffer 2 \\
\hline buffer-10 & Developed land within buffer 3 \\
\hline region & $\begin{array}{l}\text { The total number of cells (30 meters) within } \\
\text { the region }\end{array}$ \\
\hline flood-hazard-100 & $\begin{array}{l}\text { The number of developed cells within the } \\
\text { region in the 100 year flood plane }\end{array}$ \\
\hline flood-hazard-500 & $\begin{array}{l}\text { The number of developed cells within the } \\
\text { region in the 500 year flood plane }\end{array}$ \\
\hline total-buffer-1 & $\begin{array}{l}\text { Total area in buffer 1 which is either } \\
\text { developable or developed }\end{array}$ \\
\hline total-buffer-5 & $\begin{array}{l}\text { Total area in buffer } 2 \text { which is either } \\
\text { developable or developed }\end{array}$ \\
\hline total-buffer-10 & $\begin{array}{l}\text { Total area in buffer 3 which is either } \\
\text { developable or developed }\end{array}$ \\
\hline total-region & $\begin{array}{l}\text { The total area in the region which is } \\
\text { developable }\end{array}$ \\
\hline
\end{tabular}

Table E2. Summary of the fields contained in the raw output of the MVA analysis.

\begin{tabular}{|l|l|}
\hline OBJECTID & Definition \\
\hline INSTALL & Installation Name \\
\hline A & Population Density from Land Scan Buffer 1 \\
\hline B & Population Density from Land Scan Buffer 2 \\
\hline C & Population Density from Land Scan Buffer 3 \\
\hline MAX_A & Max Population Density Buffer 1 \\
\hline MIN_A & Min Population Density Buffer 1 \\
\hline MAX_B & Max Population Density Buffer 2 \\
\hline MIN_B & Min Population Density Buffer 2 \\
\hline MAX_C & Max Population Density Buffer 3 \\
\hline MIN_C & Min Population Density Buffer 3 \\
\hline buffer_1 & Growth Rate (from Rug) buffer 1 \\
\hline buffer_5 & Growth Rate (from Rug) buffer 2 \\
\hline buffer_10 & Growth Rate (from Rug) buffer 3 \\
\hline
\end{tabular}




\begin{tabular}{|c|c|}
\hline OBJECTID & Definition \\
\hline MIN_buffer_1 & MIN Growth Rate Buffer 1 \\
\hline MIN_buffer_5 & MIN Growth Rate Buffer 2 \\
\hline MIN_buffer_10 & MIN Growth Rate Buffer 3 \\
\hline MAX_buffer_1 & MAX growth Rate buffer 1 \\
\hline MAX_buffer_5 & MAX growth rate buffer 2 \\
\hline MAX_buffer_10 & MAX growth rate buffer 3 \\
\hline Growth_1mile & $\begin{array}{l}\text { Normalized score (based on input values) } \\
\text { growth rate buffer } 1\end{array}$ \\
\hline Growth_5mile & $\begin{array}{l}\text { Normalized score (based on input values) } \\
\text { growth rate buffer } 2\end{array}$ \\
\hline Growth_10mile & $\begin{array}{l}\text { Normalized score (based on input values) } \\
\text { growth rate buffer } 3\end{array}$ \\
\hline Pop_Den5 & $\begin{array}{l}\text { Normalized score (based on input values) pop } \\
\text { density buffer } 2\end{array}$ \\
\hline Pop_Den1 & $\begin{array}{l}\text { Normalized score (based on input values) pop } \\
\text { density buffer } 1\end{array}$ \\
\hline Pop_Den10 & $\begin{array}{l}\text { Normalized score (based on input values) pop } \\
\text { density buffer } 3\end{array}$ \\
\hline Final_score & Finalized Sum Score \\
\hline total_flood_hazard_100 & $\begin{array}{l}\text { The total amount of land in the region in the } \\
100 \text { year flood hazard zone at the start. }\end{array}$ \\
\hline total_flood_hazard_500 & $\begin{array}{l}\text { The total amount of land in the region in the } \\
500 \text { year flood hazard zone at the start. }\end{array}$ \\
\hline PDev_100FP_YearO & $\begin{array}{l}\text { Percentage of the developed land which is in } \\
\text { the flood plane at year } 0 .\end{array}$ \\
\hline PDev_100FP_Year2 & $\begin{array}{l}\text { Percentage of the developed land which is in } \\
\text { the flood plane at year } 2 \text {. }\end{array}$ \\
\hline PDev_500FP_YearO & $\begin{array}{l}\text { Percentage of the developed land which is in } \\
\text { the flood plane at year } 0 .\end{array}$ \\
\hline PDev_500FP_Year2 & $\begin{array}{l}\text { Percentage of the developed land which is in } \\
\text { the flood plain at year } 2 \text {. }\end{array}$ \\
\hline
\end{tabular}




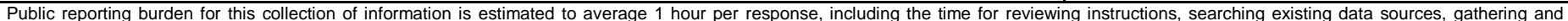

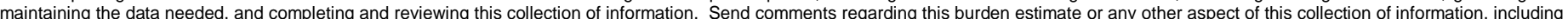

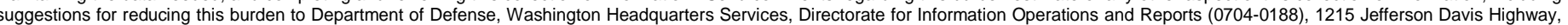

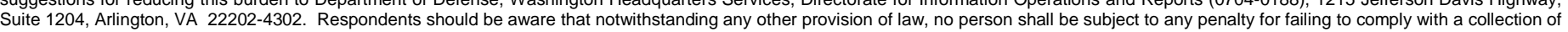
information if it does not display a currently valid OMB control number. PLEASE DO NOT RETURN YOUR FORM TO THE ABOVE ADDRESS.

1. REPORT DATE (DD-MM-YYYY) $\quad$ 2. REPORT TYPE

September 2017

4. TITLE AND SUBTITLE

Quantifying Impacts of Urban Growth Potential on Army Training Capabilities

6. AUTHOR(S)

Juliana M. Wilhoit, Scott A. Tweddale, Michelle E. Swearingen, and

James D. Westervelt

3. DATES COVERED (From - To)

5a. CONTRACT NUMBER

5b. GRANT NUMBER

5c. PROGRAM ELEMENT NUMBER

622720A896

5d. PROJECT NUMBER

P2 402188

5e. TASK NUMBER

5f. WORK UNIT NUMBER

7. PERFORMING ORGANIZATION NAME(S) AND ADDRESS(ES)

U.S. Army Engineer Research and Development Center

Construction Engineering Research Laboratory

8. PERFORMING ORGANIZATION REPORT NUMBER

P.O. Box 9005

Champaign, IL 61826-9005

ERDC/CERL TR-17-34

9. SPONSORING I MONITORING AGENCY NAME(S) AND ADDRESS(ES)

Office of Assistant Secretary of the Army for Acquisition, Logistics, and Technology

1400 Defense Pentagon

Washington, DC 20314-1000
10. SPONSOR/MONITOR'S ACRONYM(S)

ASA(ALT)

11. SPONSOR/MONITOR'S REPORT NUMBER(S)

\section{DISTRIBUTION / AVAILABILITY STATEMENT}

Approved for public release; distribution is unlimited.

\section{SUPPLEMENTARY NOTES}

\section{ABSTRACT}

Building on previous studies of urban growth and population effects on U.S. military installations and training activities (e.g., Wilhoit et al. 2016), this report describes methodology and applies a methodology for quantifying urban development and encroachment impacts. The authors propose a distance-weighted assessment of population growth around the training areas to include both current population and projected urban growth. The results of this study demonstrate improvement over the previous methodology.

\section{SUBJECT TERMS}

Military bases--United States; Endangered species; Climatic changes; Environmental impact analysis;

United States. Endangered Species Act of 1973

\begin{tabular}{|c|c|c|c|c|l|}
\hline \multicolumn{2}{|l|}{ 16. SECURITY CLASSIFICATION OF: } & $\begin{array}{l}\text { 17. LIMITATION } \\
\text { OF ABSTRACT }\end{array}$ & $\begin{array}{l}\text { 18. NUMBER } \\
\text { OF PAGES }\end{array}$ & $\begin{array}{l}\text { 19a. NAME OF RESPONSIBLE } \\
\text { PERSON }\end{array}$ \\
\hline $\begin{array}{c}\text { a. REPORT } \\
\text { Unclassified }\end{array}$ & $\begin{array}{c}\text { b. ABSTRACT } \\
\text { Unclassified }\end{array}$ & $\begin{array}{c}\text { c. THIS PAGE } \\
\text { Unclassified }\end{array}$ & SAR & 69 & $\begin{array}{l}\text { 19b. TELEPHONE NUMBER (include } \\
\text { area code) }\end{array}$ \\
\hline
\end{tabular}

